\title{
LITIGIOS POR LA TIERRA Y "MALFETRIAS" ENTRE LA NOBLEZA MEDIEVAL CASTELLANO-LEONESA
}

por

\section{ISABEL ALFONSO}

Centro de Estudios Históricos, CSIC.

RESUMEN: Los procesos de disputas por la tierra, manifestación más frecuente de concurrencia aristocrática, son analizados en este artículo como medio de entender aspectos importantes de la dinámica política local, considerada ésta como el conjunto de acciones dirigidas a negociar y reproducir relaciones de poder en tal esfera. Al identificar los campos donde se plantea de forma inevitable, aunque no siempre abierta, la competición y asumir como estructurales determinados antagonismos, en este caso entre los grupos dominantes, estamos igualmente en condiciones de comprender mejor no sólo las distintas formas que reviste la alianza o solidaridad entre ellos sino también la relación que puede darse entre distintas formalizaciones de la lucha politica. Los cambios en la utilización de recursos juridicos han de entenderse en relación a estos procesos y no al revés.

Palabras clave. Edad Medja. Tierra. Poder. Disputas, Acción política. Violencia. Derecho. Nobleza. León. Castilla.

ABSTRACT The processes of land disputing, the most frequent form of aristocratic competition, are analysed in this article as a means to the understanding of important aspects of local political dynamics, this being understood as the set of actions aimed at negotiating and reproducing power relations at the local level. When we have identified the arenas in which such competition is inevitably located (even though not always in an explicit manner), and when we have identified some patterns of antagonism as structural (that is to say, in this instance, to dominant groups) then we are in a position to understand better, not only the different forms that mutual alliance and the solidarity between aristocrats take, but also the realtionships that can develop between different versions of political struggle. The changes in the use of appeals to law have to be understood in the framework of these processes, and not vice versa.

KEY wORDS: Middle Ages, Land disputes. Power. Law. Violence. Political action. Nobility. Leon. Castile.

Hispania, LVI1/3, núm. 197 (1997) 917-955 
La complejidad de las relaciones entre aristocracia laica y eclesiástica durante la edad media es cada vez más conocida. Sabemos de la generosidad de los nobles hacia las instituciones religiosas y de la importancia de su interesada y variada vinculación a las mismas, también conocemos su agresividad y violencia hacia éstas. Parecería por lo que acabamos de señalar que las alianzas entre unos y otros grupos corrían parejas con sus antagonismos, un poco, como la misma documentación de donaciones y querellas muestra. Sin embargo, en la interpretación más generalizada los litigios por la tierra entre laicos y eclesiásticos, al tener en cuenta sobre todo su dimensión jurídico-económica, son explicados como actos de defensa de sus patrimonios respectivos, en momentos puntuales y separados de la relación global entre ellos.

Efectivamente, es frecuente ver ya desde el siglo $\mathrm{x}$, a los monasterios litigando con laicos que han reclamadado bienes en alguna medida relacionados con el patrimonio donado por sus antepasados. A veces el pleito se presenta como promovido por el propio monasterio, querelloso de las demandas y/o usurpaciones que se le hacen y deseoso de mostrar públicamente el documento escrito que pruebe lo injusto de éstas y, al mismo tiempo, conseguir ratificación de esos bienes y promesas de que no serán perturbados en el futuro. Son este tipo de reclamaciones las que parecen avalar la visión de unos patrimonios eclesiásticos continuamente amenazados por las ambiciones y rapiñas de una nobleza laica siempre hostigante, de cuya violencia se proclaman víctimas. Pero las pretensiones, más o menos violentas, de los mismos nobles sobre esos bienes permiten la otra versión, no diferente substancialmente de la anterior, que los presenta actuando en defensa de unos patrimonios familiares cada vez más afectados por la fragmentación hereditaria y la liberalidad piadosa de sus miembros y, en definitiva, reaccionando ante el poder creciente de la iglesia '.

Esos dos aspectos de lo que, en definitiva, constituye un mismo argumento suelen relacionarse con el desarrollo de un derecho de propiedad privada, defendido por los monasterios, frente a un derecho protector del patrimonio familiar, defendido por los laicos; y con una situación de debilidad o crisis de autoridad política central, que sería aprovechada por los nobles para acosar los patrimonios eclesiásticos. El fenómeno es europeo y también las explicaciones señaladas -que evidentemente suelen ser más matizadas- son compartidas por la historiografía de estos países.

Estudios recientes que inciden en los aspectos sociopolíticos de las transferencias de tierra más que en los jurídicos, religiosos o puramente económicos, permiten formular cuestiones de interés para entender de un modo más complejo estos enfrentamientos. La tierra, la fuente misma de todo poder y riqueza en las sociedades medievales, constitura también el nexo de relación predominante en todos los estratos sociales. En torno a ella y su control se articulaban distintos vínculos personales y sociales. De ahí que ni donaciones

1 Para esta visión cotrapuesta WeIngerger, S., «Cours judiciaires, justice et responsabilité sociales dans la Provence mediévale: $\mathrm{x}^{\mathrm{c}}-\mathrm{xI}^{\mathrm{e}}$ siécles» Revue Historique, 542 (1982), págs. 273-289.

Hispanic, LVI]/3, núm. 197 (1997) 917-955 
ni reclamaciones puedan ser explicadas por simples factores económicos pues unas y otras estan relacionadas con redes sociales locales ${ }^{2}$.

Estas páginas se centran sobre un conjunto de disputas por la tierra ${ }^{3}$ entre instituciones religiosas y grupos o individuos de la nobleza que tuvieron lugar entre los siglos XI-XIV en el área castellano-leonesa. El propósito es analizar lo que considero, a manera de hipótesis, una dinámica de negociación de relaciones políticas locales formalizada en torno a tales disputas, tratando igualmente de identificar los elementos estructurales que subyacen a la misma. La comprobación de tal hipótesis ha de repercutir en la interpretación que hagamos de los procesos de cambio legal e institucionalización política en una forma sobre la que reflexionaremos en el apartado final.

Para ilustrar esta dinámica social, que propongo interpretar como más inherente y estructural al propio sistema de lo que se ha asumido, me he valido de una serie de casos cuyos protagonistas, por la información que nos proporcionan otros estudios, pueden ser identificados y relacionados entre sí y con los centros religiosos con los que pleitean, que permite observar no sólo una vinculación más larga, anterior y posterior al litigio, sino también ver cómo es heredada y negociada por sus descendientes ${ }^{4}$. Son casos proceden-

2 Son estudios que recuperan y desarrollan el concepto de intercambio de dones de MAUss, M., en su clásico «Essai sur le don» en Sociologie et Anthropologie, Paris, 1950, entre ellos White, S., Custom, Kinship and Gifts to Saints. The "Laudatio Parentum" in Western France, 1050-1250, Chapetl Hill and London, 1988; Rosenwein, B., To Be Neighbor of St. Peter: The Social Meaning of Cluny's Property, Ithaca, 1989; MILLER, W., Bloodtaking and Peacemaking. Feud, Law, and Society in Saga Iceland, Chicago and London, 1990; más recientemente este tratamiento social de la propiedad en los artículos recogidos en Davies, W., y Foruracre, P., Property and Power in Early Medieval Europe, London, 1996

3 Se usa el término tierra en un sentido muy amplio para todo un conjunto de bienes motivo formal de las querellas, su contenido se especificará en cada caso, sin abordar sino indirectamente la distinción entre propiedad dominical y señorial.

4 Estudios sobre la aristocracia que son referente y base importante de este trabajo son los de MARtínez Sopena, P., La Tierra de Campos Occidental. Poblamiento, Poder y Comunidad del siglo x al XII, Valladolid, 1985 (en adelante Tierra de Campos); «Parentesco y poder en León durante el siglo XI. La "casata" de Alfonso Díaz), Stvdia Historica, V, 1987 (en adelante «La casata»); «El conde Rodrigo de León y los suyos. Herencia y expectativa del poder entre los siglos xu y XIJ» en PASTOR, R., Relaciones de poder, de producción y de parentesco en la Edad Media y Modema, Madrid 1990; «La nobleza de León y Castilla en los siglos XI y XII. Un estado de la cuestión» en Hispania, 185, (1993). Se han utilizado igualmente de ESTEPA, C., Estructura social de la ciudad de León (siglos XI y XII), León 1977 (en adelante Estructura); «Poder y propiedad feudales en el periodo astúr: las mandaciones de los Flaínez en la montaña leonesay, en Misceal lania en homenatge al P. Agusti Altisent, Tarragona, 1991. Para una muy útil comparación el reciente libro de Alvarez, I., Poder y relaciones sociales en la Edad Media. Los territorios entre el Arlanzón y el Duero en los siglos $\mathrm{X}$ al $x N$, Salamanca, 1996. Otros estudios serán citados en las notas correspondientes. Sobre la importancia que para la aristocracia tuvo el control de, o la vinculación a, monasterios pueden verse además de los anteriores LoRING, M. I., «Nobleza e iglesias propias en Cantabria altomedieval», Stvdia Storica, V (1987); de la misma "Dominios monásticos y parentelas en la Castilla altomedieval: el origen del derecho de retorno y su evolución» en PASTOR, R., (comp.) Relaciones de poder, de producción y de parentesco en la Edad Media y Modema, Madrid, 1990; MARTINEZ SOPENA, P., «Monasterios particulares, Nobleza y Reforma eclesiástica en León entre los siglos Xl y XII», en Estudios de Historia Medieval. Homenaje a Luis Suárez, Valladolid, 1991 , 
tes fundamentalmente de los fondos documentales de dos instituciones eclesiásticas: catedral de León y monasterio de Sahagún que he seleccionado antediendo a los criterios señalados ${ }^{5}$.

Este criterio selectivo obedece a la asunción explícita de algunas aportaciones de la Antroplogía jurídica que considero básicas, que ya han sido desarrolladas y mostrado operativas en estudios históricos, aquí destacaré dos ${ }^{6}$ :

- una disputa judicial es sólo un momento de un conflicto más amplio, por lo que la comprensión de la misma ha de atender al contexto de relaciones previo y posterior a la misma, es decir, debe ser entendida dentro del proceso social más general en el que tiene lugar.

- acudir ante los tribunales constituye una estrategia entre otras en el curso de un conflicto, por lo que las repercusiones de utilizar ese foro para hacer públicas unas demandas y tratar de encontrar solución a las mismas ha de tener en cuenta la legitimidad que en cada caso puede otorgar una decisión judicial, pero también otros medios de resolución posibles y la relación más que oposición entre unos y otros.

A mediados del XI tres pleitos permiten plantear algunas cuestiones relativas a la propiedad y tenencia de tierra y las relaciones sociales trabadas en torno a la misma. Permiten indagar además los problemas que los cambios de titularidad, por transmisiones entre titulares o por muerte de uno de ellos, provocan entre las gentes a ellos vinculadas. Es así como creo hay que entender unos conflictos que enfrentan a la familia de la condesa Sancha Muñiz, fundadora del monasterio de San Antolín, y a la Catedral de León con gentes que disputan sus posesiones, y las formas de resolverlos ?.

5 RUIZ ASENCIO, J. M., Colección documental del Archivo de la catedral de León vol. III y IV (986-1 109), León 1997,1989; FERNANDEZ CaTON, J. M., Colección documental del Archivo de la catedral de León vol, V y VI (1109-1230), Madrid, 1990, 1991; Herrero, M., Colección diplomática del monasaterio de SAhagún, vol. II y III (1000-1109), León, 1988; FERNÁNDEZ FLoreZ, J. A. , Colección diplomática del monasterio de Sahagún, vol. IV y V (1110-1300), León, 1991, 1994 (en adelante citare año/CL, núm. de documento y año/SHG, núm. de documento respectivamente)

6 EPSTEIN, A. L., "The case method in the field of Law» The Craft of Social Anthropology, London, I967; COMAROFF, J., y RoBerTs, S., Rules and processes: The Cultural Logic of Dispute in an African Context, Chicago, 1981. Algunos estudios de historia medieval donde se han aplicado, WHITE, S., "Pactum...Legem Vincit et Amore Judicium": The Settlement of Disputes by Compromise in Eleventh-Century Western France», en American Joumal of Legal History, 22, 1978; del mismo «Feuding and Peacemaking in Touraine Around the Year 1100" en Traditio, 42, 1986; Davies, W., y Fouracre, P., The Settlement of Disputes in Early Medieval Europe, Cambridge, 1986; Miller, W., Bloodtaking: también en AlFonso, I., «Resolución de disputas y prácticas judiciales en el Burgos medievaly, Burgos en la Plena Edad Media. III Jornadas Burgalesas de Historia, Burgos, 1994, (págs. 2111-243)

7 Los pleitos: 1043/CL, 1066; 1067/CL, 1151; 1045/CL, 1151; 1031 [1087-1112]. Los otros documentos citados 1038/CL, 970, 971; 1040/CL, 992. Sobre el monasterio de San Antolín y la familia de sus fundadores SER, G. del, «Un monasterio benedictino leonés olvidado: San Antolín» en Semana de Historia del montacato cantabro-astur-leọnés, Oviedo, 1982, págs. 175-194.

Hispania, LVIV/3, nüm. 197 (1997) 917-955 
La condesa Sancha, descendiente del conde Munio Fernandez, en 1043 recibe en la villa de Cimanes de un grupo familiar sus hereditates proprias que dicen tener de comparationes y ganantias y donar libremente y sin presión alguna (corde puro, mente deuota et spontanea uoluntate). No se expresa el motivo de dicha donación, y podría pensarse en es una más de tantas donaciones hechas por pequeños propietarios a uno de los grandes. Sin embargo, otro documento de la misma fecha ${ }^{8}$ nos informa que esa entrega de bienes forma parte de la materialización de un ritual de perdon. Esas gentes habían pretendido violentamente, según la narración, como homines forciosos, las heredades que tenían en préstamo del conde Munio Fernández y después de su hijo Pedro Muñiz, padre y hermano respectivamente de la receptora de la donación.

Se nos dice también que ese «levantamiento» tuvo lugar en la minoría del ultimo heredero de la villa y cuando éste la transmitió al monasterio de San Antolín. Dos circunstancias que me parece importante resaltar y que más tarde discutiré con más detalle pues está documentada esa transmisión. Es decir, que se reconoce un estallido de violencia ante cambios de titular señorial, cambios que afectan a los vínculos personales y materiales existentes, que pueden ser aprovechados por las dos partes para mejorar su situación, su posición tanto respecto a los bienes que tienen como a las obligaciones debidas por los mismos, que en cualquier caso es necesario negociar. Tal vez aquí sea más importante la transmisión de la villa a una institución religiosa que la transmisión en la misma línea familiar.

En cualquier caso sigue la narración contando cómo la disputa, el conflicto es llevado ante Fernando I por la condesa Sancha ${ }^{9}$, que es tía del menor, como sabemos. En esa iuncta en Sahagún a la que el rey ha convocado a totos suos barones, la condesa muestra la carta de cesión de Vermudo II a su padre de los bienes en litigio, que sirve a la curia regia para ratificarlos. No conocemos los argumentos de la otra parte pero esa prueba escrita puede indicar que lo que los hombres disputaban era la propiedad de esas tierras al heredero menor, no la tenencia en préstamo.

Me parece de mayor interés preguntarnos por el significado de la existencia del propio litigio judicial, que tal vez pueda indicarnos algo de la naturaleza del conflicto y del posible estatus de los litigantes con la condesa. ¿por qué la condesa ha de llevar ante el rey la resolución de esta disputa? ¿por qué su jurisdicción no es suficiente para imponerse a esos hombres de Cimanes?. Este planteamiento permite interrogarnos sobre la práctica de la justicia señorial ¿a qué ámbito abarca y qué eficacia tiene? otros documentos nos muestran a esta misma condesa, también a su padre anteriormente, reci-

8 El editor incluye estos documentos juntos, advirtiendo que en el Tumbo fueron copiados separados tal vez, supone, por proceder de dos pergaminos. Juego con la idea de que se hubiese perdido el que vamos a comentar después, hecho que debió ocurrir a menudo como se demuestra también por los siguientes, y que al escamotear parte de la información registrada propicia conclusiones muy diferentes respecto a los motivos de tantas donaciones.

9 Considero un error que se diga por Munio Fernández. 
biendo algunos bienes en concepto de iudicato, indicio de su poder judicial. ¿Acaso la justicia de los señores solo sirve para dilucidar casos entre sus dependientes? ¿se trata de un conflicto por someter a gentes que no dependen dominicalmente de ellos? ¿los conflictos en los que ellos son una parte han de ser resueltos en instancias superiores? ¿tal vez esta «debilidad» es debido a la condición femenina del poder en este caso? ¿Qué pensar de los litigantes? ¿propietarios-prestameros de sus tierras, cuál es su estatus social? Sus tierras - de ganancia y de compra- son denominadas heredades $¿$ son notables locales que negocian de este modo sus relaciones con los grandes, a cada cambio de titular, primero violentamente, después judicialmente?

Otros diplomas permiten contextualizar algo más el conflicto. La dotación de la iglesia de San Antolín en 1038, no parece ajena al mismo, pues se convierte en el nuevo titular de las heredades y villas de la familia de Sancha Muñiz. No sólo eso sino que la entrega que de este monasterio hace en 1040 esta condesa a la catedral de León, junto con el de San Salvador en Baradones incluyendo las villa de Cimanes, afecta sin duda, a las relaciones de poder local ${ }^{10}$.

Podemos ver que los conflcitos estallan de nuevo años más tarde, cuando Havive Donniniz, un sucesor de los anteriores "representando a los suyos reclama (calumpnia) al obispo de León sus derechos sobre cortes y heredades en Cimanes y en Matilla. Su argumento es la compra que había hecho su padre de las mismas a Pedro Muñiz, el hermano de doña Sancha. El obispo le emplaza ante Alfonso VI argumentando que los bienes disputados habían sido donados a San Antolín. Son nuevamente argumentos opuestos sobre hechos, si o no han sido vendidos o cedidos a uno $u$ otro. La reclamación de Havive es pública: calumpnia, reclama, invocando derechos hereditarios, basados tanto en herencia como en compra. Alegato que todos entienden, pero que hay que demostrar.

El obispo, a través del tenente de los bienes que Havive reclamaba, acude ante el rey, ad diem placiti in concilio, que tiene lugar en Quejida, a orillas del Esla, con la primitiva carta de donación regia a Munio Fernández y los datos de su transmisión hasta él ya conocidos ${ }^{12}$. Lo que interesa es esta legitima-

10 No quedan claras las razones por las que la condesa dispone de los bienes de su sobrino en favor de la Catedral. El hecho es interpretado por G. del Ser ( $U$ Un monasterio» pág. 184), como un acto para proteger los derechos amenazados del menor por el conflicto comentado. Cabe, sin embargo, pensar que la donación que el sobrino hace poco después al monasterio y no a la catedral, en la que aparecen confirmando algunos de los miembros de la familia Orvida, los litigantes con doña Sancha anteriores, puede ser expresión de intentos monásticos por mantener autonomía respecto a la catedral y si es así ¿podria pensarse también en tensiones intrafamiliares que aglutinaran a sectores de la comunidad de Cimanes en torno al heredero menor frente a su tía?

II Se puede admitir cierta relación por los antecedentes que plantea al caso.

12 Primero al hijo y después al nieto quien, en contra del argumento de Havive, lo habría cedido a San Antolin, donde se dice fue enterrado, y donde cultor et domina era su tía la condesa Sancha. Se cuenta como ésta ya había devindicado ante Fernando I esos bienes de los «heredes antecesores» del litigante actual que habrian recibido de doña Sancha por su renuncia el precio pagado por las heredades, precio que coincide con lo recibido por los litigantes de 1043, por lo que hemos de pensar que Havive si no pertenecía al mismo grupo, los paralelismos, las formulas eran idénticas.

Hispania, LVIU/3, núm. 197 (1997) 917-955 
ción de una reclamación por referencia a litigios anteriores y resultados favorables, pues la agnitio y compromiso de no inquietar más esas heredades es lo que en el argumento episcopal hace inualide la reclamación de Havive al rey. Parecería que estos datos deberían haber servido para probar la querella episcopal, de hecho se dice que el rey Alfonso y sus magnates vieron scripture ueritatis de parte del obispo. Sin embargo, deciden que el obispo dé diez testimonios igual que Havive, y que éste eligiera tres para ratificar las afirmaciones del primero, jurando que nunca sus antecesores habián sido heredes en esas villas, sino prestameros de la condesa Sancha. Es entonces cuando se produce el reconocimiento de Havive de la indecencia de sus argumentos y la renuncia a posteriores querellas.

Entre los diez testigos de apoyo del obispo cuyos nombres se escriben al final conviene destacar que se encuentran infanzones que posteriormente volveremos a encontrar pero como adversarios suyos: Pelayo y Cipriano Vellitiz, o Citi Donelliz, Diego Ovéquiz...

Podemos preguntarnos de nuevo ante estos datos por los motivos de llevar el pleito ante el rey. Sin duda, uno de ellos es la imposibilidad o los límites del poder del obispo para imponerse a estos notables locales. Pero otro, el foro privilegiado que para sus demandas suponía el concilio regio, forma de publicitar su dominio y sus alianzas, aumento de su prestigio. Que la victoria episcopal, sin embargo, no es tan rotunda como podría pensarse por este único documento, que el litigio podía proseguir después de una adjudicación tan rotunda como la anterior, que la reclamación de tierras con argumentos de posesión anterior, contestando aparentemente los derechos del titular actual, debieron formar parte de las estrategias políticas de estos grupos de heredes ante cambios en situación política, parece mostrarlo el hecho de que el mismo día en que resulta vencido, Havive firme un pacto con el obispo por el que recibe la villa de Colinas en préstamo haciéndose su vasallo.

Recapitulemos sobre estos casos:

- Se llevan ante la curia regia de Fernando I y de Alfonso VI.

- En ambos los argumentos son sobre la condición de sus derechos, préstamos o propiedad. Discutiéndose y legitimándose los mismos en funcion de la forma en que se dice se han cedido y transmitido. La memoria alegada se extiende a diferentes transmisiones de los primeros propietarios entre sí y con instituciones, de los receptores entre sí y por compra a los primeros. Se discute, por tanto, igualmente si la tierra disputada ha sido cedida o vendida, pues en este caso los derechos no son de simple tenencia ${ }^{13}$.

- En los dos casos las pruebas son la carta de la primitiva donación regia que pasa con los bienes a cada receptor. En el primero Fernando I y sus barones parecen decidir basándose en este documento a favor de los que

13 Sobre los problemas y conflictos a que estan sujetas las transacciones, la necesidad de su continuada redefinición porque a través de ellas se busca definir y determinar estatus y relaciones sociales, son muy interesantes los comentarios de MizLER, W., Bloodtaking, pág. 80. 
lo presentan, y según ordena la lex manda entregar el doble o triple de lo disputado y una parte al rey; en el segundo caso, sin embargo, Alfonso VI junto con sus magnates, exigen también juramento de testigos, hecho que se presenta como el motivo de la renuncia de su oponente.

- En el primer caso no se cumple la resolución regia pues los vencidos suplican perdón donando sus bienes en el lugar disputado por los que reciben el precio que supuestamente habian pagado por ellos; en el segundo, la parte vencida reconoce lo erróneo de su demanda y afirma la propiedad del obispo, pero no entrega nada, y recibe, en documento separado, el préstamo de otra villa que se insiste tendrá in quantum fuero uestro uasallo.

Estos casos muestran las dificultades que a nivel local encuentra la aristocracia laica y eclesiástica para el ejercicio de su poder tanto patrimonial como jurisdiccional. La dinámica de relaciones entre ellos y los notables locales, que en los casos anteriores no parece tengan estatus noble, se manifiesta en estas disputas. Vinculados a los primeros mediante tenencias y préstamos, tal vez esa dinámica no difiera mucho de la que se da entre niveles más altos. Es necesario comparar con otras situaciones y otros momentos. Reclamaciones hereditarias y concesiones prestimoniales son hechos frecuentemente consecutivos ya en el siglo XI ¿Podemos considerarlos forma usual de negociar tenencias y relaciones en determinados niveles sociales, el medio o vía por la que se aclara también la transmisión dentro del grupo con expectativas de herencia y el lugar social que marca la misma? El obispo logrará que la villa de Cimanes al final pase completamente bajo su control, pero las gentes que se la disputaban consiguen mantenerse en la red episcopal y disfrutar de las ventajas que ésto puede proporcionarles tanto económica como social y políticamente.

Otro conjunto de casos, en torno a Villa Asper ${ }^{14}$, pueden ser buen ejemplo de reclamación hereditaria que plantean a un monasterio, en este caso el de Sahagún, descendientes de primeros o anteriores donantes. Se trata de un grupo familiar cuya madre pertenece a la nobleza magnaticia, los Alfonso, y el padre a la nobleza local, los Velázquez ${ }^{15}$. Debió ocurrir a la muerte de la madre María Núñez, que sabemos sobrevivió en unos años al padre, Munio Velázquez. Los litigantes son sus tres hijos y una sobrina que pretenden continuar en la posesión de esa villa que dicen su padre había permutado con los monjes de Sahagún. Estos, sin embargo, recordaran al rey Alfonso y los magnates de su palacio, ante los que llevan la querella, que habian cedido a sus padres la tenencia de forma vitalicia, por lo que a su muerte debía revertir a su monas-

14 Los docurnentos que se comentan: 1096/SHG, 993; 1131/SHG, 1247;

is Sobre esta familia los datos principales en MARTínez SOPENA, P., «La casata» pág. 65, quien relaciona estas reclamaciones con otras de miembros de la misma familia Alfonso e interpreta como expresión de defensa patrimonial de ese linaje en la coyuntura de fines del siglo XI.

Hispania, LVII/3, núm. 197 (1997) 917-955 
terio. Añaden los monjes que por ese beneficio Munio Velázquez y su mujer les habían donado la porción que tenían en el monasterio de San Felices.

Ante el rey, pues, argumentan unos que hubo testamentum conmutacionis, los otros cesión temporal. No se discuten hechos, la cesión monástica de la villa, que no se pone en duda sino las condiciones de esa cesión, es decir en alguna medida, derechos de una y otra parte ${ }^{16}$. No se presentan, ni se les exigen, pruebas de ningún tipo, aunque las dos partes parecen estar en condiciones de presentar los documentos que respalden sus pretensiones. La decisión regia es que cada uno vuelva a su propiam hereditatem. ¿Qué mejor forma de reiniciar de nuevo el ritual de intercambios? Es lo que realmente hacen pues los herederos ratifican la donación de lo que tienen de su madre en el monasterio de San Felices (nostra hereditate o porcionem nostram), que en cierto modo recuperan por la decisión regia, y también la relación con los santos monásticos a los que hacen sus patronos. Los monjes les conceden otro monasterio, el de San Andres de Pozadurama. El hecho de que esta transacción se estabilice como conmutación parece implicar la transferencia completa y para siempre de tales bienes, que las dos partes se comprometen respetar.

El interés del diploma es indudable por cuanto nos informa de una cesión con claro carácter beneficial, incluso formalmente, de mediados del XI. El monasterio había concedido a Munio Velázquez pro beneficio una villa lejana al centro monástico para que vindicaret y tuviese durante su vida. Es decir, defensa y disfrute vitalicio. A cambio ese noble con su mujer habian donado su porción en el monasterio familiar de San Felices. La vinculación es clarisima y también la naturaleza de la misma. Los hijos parecen estar tratando en el caso comentado de reafirmar estos lazos, de afirmarse como herederos de esa relación, de continuar vinculados a la poderosa red de Sahagún. Su estrategia es conocida, reclamar sus derechos sobre los bienes que sirvieron para entablar los vínculos anteriormente, reclamación que ahora les va a permitir desde una posición más fuerte volver a donar su parte en el monasterio de San Felices ya donado por lo padres y al hacerlo proclamar, en un foro privilegiado como es la asamblea regia, sus lazos de sangre con los propietarios de ese monasterio, los poderosos Banu-Mirel ${ }^{17}$. Si aceptamos el menor nivel social de esta rama familiar, no deberíamos minusvalorar la importancia de estos rituales de afirmación pública de unos vínculos que constituyen su

16 Otro tipo de permutas realizadas por la misma institución pueden servinos de referencia para comprobar la variedad con que podian concretarse este tipo de negocios. En 1102 (SHG,1085) el cambio que Sahagún hace con Pedro Ansúrez es para siempre sicut lex gotica docet. Interesante el respaldo juridico para este intercambio que pudo proporcionar a Velasco Muñoz que presencia el acto los argumentos normativos usados en la reclamación que comentamos. Sin embargo, dos años más tarde en 1104 (SHG,1 104), el intercambio que hace Sahagún con otro laico, reviste las mismas condiciones que una concesión prestimonial pues lo concesionarios, que por este acto se convierten en vasallos monásticos, deberan retornar a su muerte lo que adquieren en la connutación.

17 Los datos sobre esta familia y el monasterio de San Felices en MARTínez Sopena, P., Tierra de Campos, págs. 347-352. 
herencia inmaterial en estrecha relación, es claro, con la material. Tendríamos además, si esto es cierto, que estas actuaciones servirían igualmente y al mismo tiempo para disputar su posición y estatus dentro del amplio grupo parentelar. La lógica, por tanto, no es simplemente la de unos nobles ansiosos por reconstruir sus fragmentados patrimonios familiares, en todo caso a este concepto habría que darle un contenido más amplio que incluyera igualmente ese capital simbólico que proporciona la herencia de los vínculos sociales ${ }^{\text {t8 }}$.

La solución; propiciada por el rey, parece plenamente aceptada, Sahagún recupera Villa Asper y también le es ratificada la porción que va a completar su posesión sobre el antiguo monasterio familiar de San Felices; los hijos de Munio Velázquez y María Núñez se acogen al patronazgo monástico del primero, entregan lo que había sido tenencia de sus padres pero reciben otro monasterio, que aunque en el texto no se diga, supone la recuperación de una antigua donación realizada por su abuela y su padre ${ }^{19}$. Es evidente que no podemos conocer las razones que llevan a la preferencia por unos u otros bienes, ni las estrategias que están detrás de todo este proceso. Sin embargo, debemos retener el hecho de que Sahagún, en pleno movimiento de reforma eclesiástica a la que suele atribuirse la absorción progresiva de instituciones religiosas menores, ceda a laicos, completamente, uno de los monasterios que había recibido ya en 1055 de sus antepasados. En realidad, el problema es más complejo. Algunos documentos anteriores pertenecientes a esta familia permiten trazar una línea interpretrativa -hipotética desde luego- que apoya lo argumentado más arriba, según la cual los vínculos creados a través de limosnas y donaciones han de ser ratificados o renegociados a cada cambio generacional. Evidentemente no tenemos datos cuantitativos que apoyen esta hipotesis, pero si información suficiente para construirla y ver si es operativa. En el caso que comentamos sabemos que Munio Veláquez después de perturbar, en fecha desconocida, los bienes que junto con su madre había donado en 1055, el monasterio de San Andrés y dos solares en Villa Filal, consigue recibirlos en tenencia durante su vida. En 1191, poco despues de su muerte ${ }^{20}$ es su mujer e hijos pequeños los que actúan no sabemos en que forma, sólo que esos mismos bienes vuelven a ser renegociados, ahora conservan el monasterio de San Andrés, y entregan el de Santa María junto con los dos solares en Villa Filal. Con alguno de los hijos su viuda vuelve a donar

18 Sobre transacciones y capital simbólico Bourdied, P., El sentido práctico, Madrid, 1991, especialmente cp. 7 , págs. 189 y ss.

19 Se conserva la donación por su alma que en 1055 (SHG, 573) hacen Tegridia y su hijo Munio Velázquez a Sahagún, a cuyos santos llama patronos, de su villa propia de Becilla, añadiendo en la de Pozadurama, el monasterio de San Andrés y bienes en otros lugares. Este monasterio de San Andrés debe ser construcción familiar o, al menos, parece estar en ese momento en posesión única de la familia. En 1090 Munio Velázquez es sefor de Pozadurama, el solar familiar.

20 Es en 1090 (SHG,861) cuando se le documenta como tenente de Pozadurama confirmando una donación a Sahagún, a continuación de Pedro Ansúrez conde en Saldaña, y también en 1090 (SHG,863) es ante él que se dirime una querella de Sahagún con Ildonza Ovéquiz, pariente del mismo Munio por su mujer.

Hispania, LVI1/3, núm. 197 (1997) 917-955 
a Sahagún, esta vez la divisa que le ha correspondido entre sus heredes en Castilfalé. Son estos hijos los que a la muerte de la madre llevan la reclamación a que nos estamos refiriendo ante Alfonso VI. La recuperación o ratificación del monasterio de San Andrés de Pozadurama que reciben como resultado del litigio puede estar, por tanto, igualmente relacionada con el intento de retener el poder político que sabemos su padre ha detentado en el lugar.

En cualquier caso, lo que interesa es observar cómo en la medida que disponemos de algo más de información, el pleito judicial comentado aparece claramente como un momento en una prolongada vinculación de la familia con el monasterio. Vinculación que como hemos visto se renueva después de ese litigio aunque tal vez bajo condiciones diferentes que no siempre debieron satisfacer todas las expectativas de las partes enfrentadas. Si realmente los hijos de Munio Velázquez pretendían continuar con la tenencia y defensa de Villa Asper no lo consiguieron, aunque no cejaron en su empeño como una versión posterior del mismo pleito muestra. Es ofrecida por Sahagún en 1131, esta vez ante Alfonso VII, para apoyar su reclamación sobre esta villa ahora en posesión de Velasco Muñoz, el único hijo varón del anterior y protagonista del pleito de 1096, al que acusa de haberla entrado aprovechando la coyuntura bélica posterior a la muerte de Alfonso VI. Entramiento y violencia son los elementos que en boca del abad pretenden deslegitimar la tenencia durante largo tiempo de la villa por Velasco Muñoz. Se puede ver, de hecho así se contiene en la narración, este entramiento como un episodio más de la competición en la que están inmersos. Tal vez, sin embargo, haya que verlo también como signo de una actitud política diferente, opuesta a la tomada por Sahagún en esos conflictos bélicos en torno a la renovación de autoridad política regia que han tenido lugar. No se conservan datos en este caso para ver las posibles conexiones entre unos y otros conflictos, pero deberíamos ser precavidos al atribuir a las desmedidas ambiciones nobiliarias estas violencias.

Es posible ver la resolución de este acto judicial ante la corte regia como una ceremonia de reconciliación entre el monasterio y el noble agresor el cual reconoce, más que su violencia, su error y lo injusto de su tenencia (intelligens errorem meum quia iniuste...hereditatem de Uilla Asperi michi retinui) por lo que devuelve la carta que habían dado a su padre para dirimir términos, con la promesa de no inquietar más. Estos argumentos son similares a tantas otras renuncias que encontramos en nuestras colecciones documentales bajo los nombres de manifestum, agnitio, deffinitio. El texto comentado es una clara reconstrucción monástica, en un clima de restauración regia, de los datos que le interesa mostrar, su narración lleva implícita la lógica de la resolución a través de términos aparentemente tan asépticos como autem o itaque, que sirven para subrayar sus argumentos ${ }^{21}$. A pesar de ello, en esta narración

21 Despues de narrar como Velasco Muñoz per uim tulerat Uillam Asperi a Sancto Facundo, continua iussit, autem, eos rex ut recuperarent hereditatem ad se pertinentem, quan uiolenter perdiderant. Y añade Cognoscens, itaque Uelasco Monnionis uiolencian suam, retulit kartam quam dederant patri suo... (SH6, 1247).

Hispania, LVII/3, tuùm. 197 (1997) 917-955 
los términos de violencia son sólo utilizados por el monasterio como parte de su acusación, el reconocimiento de la misma por el laico, como he señalado, destaca de forma más indirecta que la que se encuentra en otros casos las bases legales de sus pretensiones y hasta de su actuación, que en última instancia remiten a la antigua tenencia por su padre. Ahora no va a ser castigado o penalizado por sus violencias más allá de la restitución de la villa tomada, volverá a colocarse bajo el patronazgo de los santos monásticos y a recibir por su renuncia cien sueldos de plata. Así, el pleito que comentamos es claramente un momento de ese proceso de tensiones que caracterizan las formas de interacción entre el gran monasterio y sus clientes laicos, tanto Munio Velazquez como su hijo Velasco Muñoz son confirmantes asiduos de los negocios monásticos.

Otros casos permitirán que desarrollemos nuestro argumento. Podemos aglutinarlos, en un primer momento, en torno a Villacorta, lugar que durante más de un siglo se documenta relacionado con las mismas familias que parecen utilizarlo en esa dinámica de donaciones, apropiaciones o reclamaciones, denuncias, renuncias y continuidad en tenencia. Proceso ligado a la vinculación a Sahagún y lo que ésta representa para estos grupos y a la propia relación entre ellos.

A principios de 1102 tiene lugar un pleito ante Alfonso VI, que claramente es un momento judicial de un conflicto más largo en el que según los argumentos de Sahagún se habían producido actos de violencia que califica de barbaricos. Efectivamente, por este acto el monasterio reclama heredad y divisa (diuisionem, diuisa) ${ }^{22}$ que dice tener en Villacorta por donación de Pedro Ovéquiz y su mujer Ildonza, de la que Pedro Sarracínez y suis hereditariis se habian apropiado (obsederat more barbarico). Tampoco en este litigio parece discutirse el hecho, que todos conocen, sino los derechos que lo justifican. Así Pedro Sarracínez, como queda implícito por su reconocimiento final en contrario, parece alegar que tenía en dicha villa divisa por herencia, es decir que la había recibido per directum ${ }^{23}$.

Ante argumentos contrarios y pese a la prueba escrita presentada por los monjes, el rey encarga a Pedro Ansúrez que haga una pesquisa dirigida a averiguar la verdad de las alegaciones monásticas, no de las violencias ni pretensiones hereditarias del laico. El resultado de la pesquisa confirmó el contenido del documento monástico (inuenit sicut in suo testamento habe-

22 Sobre esta nocion y el desarrollo de un poder político a partir de la propiedad de la tierra viene trabajando hace años ESTEPA, C., quien recoge sus conclusiones en «Proprieta, evoluzione delle strutture agrarie e trasformazioni sociali in Castiglia (secoli XJ-XIt) en DILCHER, G., e VIOLANTE, C., Strutture e trasformazioni della signoria rurale nei secoli $X$-XII, Annlali dell' Instituto storico italo-germanico, Quaderno 44. Bologna, 1996.

23 Pedro Sarracínez tiene cierta relación con los donantes de la villa disputada alegados por Sahagún a través de su cuñada Fronilde Ovéquiz, casada con el que supongo su hermano Ordoño Sarracínez. Sobre estas dos familias de la nobleza remito a MARTínez SOPENA, P., Tierra de Campos, págs. 361-362, y REglero, C., Los Señoríos de los Montes Torozos. De la repoblación al Becerro de las «Behetrias" Valladolid, 1993, págs. 91-94. •

Hispania, LVI1/3, nủm. 197 (1997) 917-955 
bant), y como tantas otras veces y con otro tipo de pruebas, incluso sin realizarse, funcionó como elemento de presión para forzar a una de las partes a reconocer lo equivocado o injusto de sus demandas. Se desencadena entonces todo un ritual de súplica y perdón, de ruego y misericordia, bien estudiado por Koziol ${ }^{24}$, que restablece las relaciones entre las partes, incluso sin haberse producido ningún tipo de resolución negociada. En el caso que comentamos, Pedro Sarracínez ruega al abad que la divisa disputada pudiera tenerla de por vida, hecho que el abad motus misericordia le concede, bajo compromiso de que no la reclamen ni su mujer ni sus hijos y que los de Fontecillas no inquieten a los de Sahagún. Indicación, esta última, que ilustra sobre el carácter de los problemas y diferencias que los enfrentaban.

Otro episodio pacífico de este conflicto tiene lugar dos años más tarde cuando Pedro Sarracínez, ahora con su hija, devuelve a Sahagún la tenencia de Villacorta recordando la querella y resolución anterior, aunque lo que dice entregar es mea porcione integra sobre la que habia habido contemptione ante rege ${ }^{25}$. Es una entrega solemne, tal vez hecha de nuevo ante el grupo de magnates que confirma, a la que añade su porción en otro lugar. La razón de esta devolución-donación es la recepción de otra, la heredad de Faveces que se dice fue de Diego Osóriz, igualmente en tenencia vitalicia que a su muerte devolverá con todo lo que allí inuenta fuerit, expresión ésta, como luego comentaremos, que hace referencia a la defensa del patrimonio monástico, y por tanto, al carácter de la vinculación.

El estatus social de Pedro Sarracínez lo conocemos por otro material que aporta más datos sobre las formas de acción política de esta nobleza de infanzones a la que pertenece. Por ello merece la pena que lo examinemos con cierto detalle. Primero, dado que sus hijos aparecen entre los infanzones herederos que en 1117 se enfrentan con el obispo de León por la posesión de un monasterio, voy a referirme a este conflicto del que se conservan tres importantes documentos. En segundo lugar, por su vinculación con los Ovéquiz a través del matrimonio de su hermano Ordoño Sarracínez, volveré sobre algunas disputas en las que éste y los descendientes de su mujer intervienen.

Los casos de 1093, 1115 y 1117 , protagonizados por los que podemos denominar infanzones del Bemesga son bien conocidos y estudiados, especialmente el primero ${ }^{26}$, pero su análisis comparado me va a permitir profundizar en los procesos en los que estos nobles se ven inmersos. El interés de obser. var cómo han sido registrados y su estructura narrativa me lleva a presentar a continuación una traducción aproximada manteniendo dicha estructura.

24 Kozrol, G., Begging Pardon and Favor. Ritual and Political Order in Early Medieval France, Ithaca and London, 1992.

25 Documento 1104/SHG, 1103.

26 ESTEPA, C., «Formación y consolidación del feudalismo en Castilla y León» En tomo al fell. dalismo hispánico. I Congreso de Estudios Medievales, Avila, 1989, págs. 212 214 y en Estructura, pág. 256; PASTOR, R., Resistencias y luchas campesinas en la época del creciniento y consolidación de la formación feudal. Castilla y León, siglos X-XII, Madrid, 1980, pág. 82, Los documentos son $1093 / \mathrm{CL}, 1279 ; 1115 / \mathrm{CL}, 1350 ; 1117 / \mathrm{CL}, 1358$.

Hixpania, LVII/3, núm. 197 (1997) 917-955 
Realmente el primero de ellos, de 1093, es un texto formidable para comprobar y profundizar la dinámica que pretendo estudiar, lleno de colorido parece más la narración de un cronista, con cierta admiración hacia las hazañas de los infanzones, que la de un parco escribano episcopal o real. La estructura de la narración tampoco es la usual. Comienza adelantando a los lectores la resolución final, la agnitio bajo la autoridad de Dios trino sobre intentionis que habían surgido entre el obispo Pedro de León y esos milites, non infimis parentibus ortos, sed nobiles genere necnon et potestate, qui uulgari lingua infanzones dicuntur, frase que se ha hecho famosa para referirse a estos grupos sociales cuyo estatus nobiliario queda así claramente definido por su origen familiar. A continuación se detallan los nombres de diez de ellos y los parientes que les acompañan, y se especifica que la contienda ha sido por heredades, villas y hombres en una amplia zona demarcada del Bernesga, que han de quedar tal como deciden en esta conventionem.

Continua con el relato de lo ocurrido hasta ese momento, entre el reinado de Ordoño, autor de la donación de estos bienes, y el del poderoso rey Alfonso, hijo del emperador Fernando. Es de notar la continuidad que la línea monárquica quiere señalar con esta referencia. En ese intervalo se introierunt los abuelos y padres de estos milites en las heredades, villas y hombres pertenecientes a la Iglesia, sobre las que se hace el reparto (agnitio y separatio).

Sigue la narración del pleito con frases que tratan de reconstruir la supuesta discusión que tuvo lugar ante el tribunal regio. Reclamación del obispo a esos milites de las heredades que poseían injustamente pidiendo que dejasen lo que nefarius erat y condenando, en estilo directo, como turpe...et ualde inhoneste que las heredades donadas por el rey, aforadas a potestates, sean separadas del derecho de la iglesia (ut hereditas que a parte regis Dei Ecclesie fuit dicata, aforastitis potestatibus sit de iuri nostro separata). Si esta lectura no es errónea tendríamos que los infanzones son reconocidos como concesionarios del patrimonio eclesiástico, es decir, estaríamos ante el mismo tipo de disputa que hemos visto antes. Volveremos sobre esto. Sigamos con el contraargumento que los mismos milites firmisissime et tam firmissimo adversus episcopus omnes una uoce dixerunt y de forma directa también dirigen al obispo recordando cómo la posesión de las heredades, villas y hombres reclamados, las habían obtenido sus padres y abuelos, en tiempo de muchos reyes y pontífices, de ahí que no las devuelvan sino por sentencia y mandato regio (nisi iuditio et imperio regis).

Quteda así resumida de manera muy viva lo que puede considerarse la apertura ritual del proceso, de pugna entre ellos, en la que vemos como se enfrentan directamente, sin duda ante una audiencia numerosa, como forma de desafiarse públicamente.

Prosigue el texto explicando la reacción emocional del obispo ante la ferocidad y firmeza de las palabras que había oído, llevando efectivamente su querimonia por la inquietudinem de éstos, ante el rey, en la certeza de que éste sabe en su fuero interno que los infanzones tenían las heredades injustamente. De interés comprobar como lo anterior es realmente parte de un pro-

Hispania. LVIt/3, núm, 197 (1997) 917-955 
ceso previo, directo, de pugna entre ellos, antes de decidir acudir al arbitrio regis et iuditio para que iudicauit. En la forma de presentar la decisión del obispo que se dice tomada después de oir esas palabras feroces, firmísimas y muy duras va implícita una condena de la otra parte. De este modo, se insiste en el argumento episcopal que en la narración se une con la decisión regia, tomada después de hacer pesquisa (inquisiuit ueritatem) por la que el portero del palacio episcopal recibirá todo lo que la iglesia de Dios negligenter et uiolentia militum amiserat, como así se hizo.

El texto abrevia lo que ocurre después, contando la no aceptación de la resolución real, y cómo los mismos que se dicen milites regis al ver esa orden y al obispo recibir todos los bienes, se reunieron con él y en presencia regia de nuevo disputaron (dimicarent). Es decir, estaríamos ante otra sesión judicial en la que el obispo mostró su voluntad de que recibiesen iudicum por esto. Los argumentos parecen repetirse, pues se dice que el rey oyendo a unos y otros iudicauit dar, para confirmar la decision anterior, tres clerigos de la catedral que jurasen el derecho (iusiurandi) a las heredades que inquiría el obispo. Es ante esta situación cuando los milites, nuevamente se utiliza estilo directo, se preguntaron entre sí que sacarían de ese juramento, que mejor resultaría pedir misericordia al obispo y así lo hicieron. Es de notar el pragmatismo con que se representan las estrategias utilizadas por lo laicos.

Entonces, - continua la narración- el pontífice y los milites, porque estos reconocieron su falsedad, hicieron entre sí hanc scripturam firmamenti et agnitionem testamenti de lo que había de poseer el obispo y lo que por su misericordia los mismos milites podían retener. Se detallan después por parte de la iglesia nombres de villas que se dice posee integras, excepto una o dos cortes (con heredad y sin divisa, o solas) que pertenecen a uno u otro de los infanzones querellantes (no todos los que figuran ahora, se nombran al principio, hay además corte del rey sin divisa en una de las villas); se añade que pueblen por parte de la iglesia todo lo que puedan sin que quede claro si se refiere a alguno de los lugares citados previamente o tiene sentido general.

Al final de la relación de bienes, y esto es importante como después veremos, se dice que han de devolver al obispo todas las heredades, tierras, viñas, prados, fuentes, aguas, molinos que en tiempos anteriores hasta el presente emerunt aut uim rapuerunt ab hominibus de la iglesia recibiendo el precio que entregaron por ellas y prometiendo no volver a comprar, ni siquiera por cuestión de deudas; que los hombres de la iglesia tampoco vuelvan a ser recibidos en heredades de esos caballeros, excepto iuuenibus, pueris et uiginibus excussis, quienes deberán retornar a sus casas a la muerte de sus padres, siendo expulsados de las de los caballeros si se niegan y recibiendo el obispo las heredades de los padres. Es sobre lo anterior que hacen pacto y firmísima estabilidad con penas espirituales y materiales para el que lo infrinja.

La riqueza de este documento es indudable y no pretenderé agotarla. Centraré mis comentarios y reflexiones en torno a varios puntos, pero antes con- 
viene presentar los otros dos casos dada la conexión entre ellos; se pueden considerar en cierta medida actos particulares, por referirse a un solo lugar, de aquel conflicto más amplio.

El diploma de 1115 presenta un litigio (intentio) entre el obispo Diego y un grupo de infanzones, de los que se nombra a uno y sus tres hijos, dos hombres y una mujer (Michael Rodriguiz et filios...et aliis infanzonis), por el monasterio de San Tirso en la ribera del Bermesga, en Valdecastro. Se narra cómo cada parte alegaba que era su heredad (hereditatem, hereditas). Ante lo cual, los milites, inducidos por el diablo, violenta y maliciosamente lo tomaron con sus villas, destruyendo los altares y edificios monásticos. A la vista de tanto mal (scelerus) como el perpetrado el obispo los excomulga (misit eos sub gladio anahematis). Excomunión que provoca su arrepentimiento y petición de misericordia, aunque se aluda a un juicio y testamento verdadero por el que habrían sido juzgados (quando uiderunt se stricti et recte iuditio conuicti, per uerissima testamenta etiam subiecti, pecierunt misericordiam pontifici...). Sigue el ritual acostumbrado, el obispo al ver su humildad los perdona bajo tali conuentione, que nunca más reclamasen parte de este monasterio ni de sus villas.

De este modo, Miguel Rodríguez, ahora no se mencionan otros infanzones, temiendo el día de la muerte y para lograr la gracia de la gloriosa Virgen Maria, hace pactum simul et placitum con sus hijos, tali conuentione: que al monasterio que destruyeron, perteneciente a la catedral, den las partes que allí tienen o esperaban tener. Confirman pues, sus rationes y afirman que nadie de sus parientes o extraños tendrá poder para contradecir tal heredad bajo excomunión y una pena más elevada que en el pleito anterior. Se cierra así un litigio que parece terminar con una clara victoria episcopal.

El texto de 1117 es, sin embargo, una nueva fase de este conflicto entre el mismo obispo Diego, y los que ahora se dicen herederos de San Tirso, aunque la forma de nombrarles pienso es indicativa de la complejidad de los grupos enfrentados. No el obispo por un lado y los infanzones por otro, sino tal vez, como comentaremos después, unos aliados con el primero y otros enfrentados con éste y con los otros. Veámos, la intentio por el mismo monasterio de San Tirso se dice entre el obispo don Diego y entre Pelayo Froilaz y sus hermanos con hijos de Martinus Cidiz; y entre Pedro Vermúdez y sus hermanos con hijos de Miguel Rodríguez; y entre hijos de Rodrigo Cipríaniz con hijos de Pedro Sarracínez.

Los argumentos esgrimidos eran que estos juzgaban como suyas las heredades de dicho monasterio y el obispo decía ser propio de su sede, es decir. argumentos similares a los sostenidos en 1115. Al final encuentran (postremo invenerunt), no se expresa por qué medios, que el obispo don Diego debía tener la mitad de dicho monasterio junto con los hijos de Rodrigo Cipríaniz y de Pedro Sarracínez y la otra mitad los otros caballeros antes mencionados. Por ello convenerunt in concilio e hicieron pactum simul et placitum tali uidelicet pactione, que los mismos herederos devuelvan las heredades que retienen y el obispo construya y pueble el monasterio, ponga y deponga abad, y los 
hereditarii se erijan en sus defensores, con todas la ventajas que se especifican y que luego comentaré, pues indican mejor que otros textos el contenido de estos pactos, la naturaleza de la relación que traban y por la que luchan y negocian.

Ciertamente, estas disputas se nos presentan como episodios de lucha colectiva por la tierra de unos infanzones que tendemos a considerar baja nobleza que parece resultar vencida en su poder local por el poder superior episcopal. Sin embargo, si por un lado indagamos en la propia identidad, estatus social y composición de los grupos en litigio, en sus relaciones internas y con los poderes a los que se enfrentan y reflexionamos más sobre la naturaleza de su relación con el campesinado, veremos un tejido social mucho más complejo y menos definido de lo que suele pensarse y contaremos con elementos para entender la dinámica de esa interacción que en definitiva es la que nos interesa.

Es igualmente difícil cuestionar la interpretación de estas luchas como reflejo y síntoma del período de crisis de fines del XI y comienzos del XII, de enfrentamiento ante el creciente poder y patrimonio eclesiástico señorial, pero analizar en más profundidad las disputas más documentadas puede permitir entender mejor la imbricación entre diferentes líneas de antagonismo y también cómo se percibe y representa la lucha política. Son razones que pretenden justificar la extensión con que a continuación analizaré estos casos en torno a los aspectos señalados.

No siempre es posible conocer del lado de la institución con la que se enfrentan los litigantes laicos quiénes realmente están luchando y qué intereses y estrategias ellos mismos estan practicando. La importancia de este conocimiento no puede ser eludida y ha de funcionar siempre como factor a tener en cuenta aunque no venga dado. Los siguientes comentarios pretenden demostrarlo. Los dos obispos Pedro y Diego, son tío y sobrino respectivamente. La narración convencional es como sigue: protagonistas de un período político muy conflictivo para el reino, del que también se resiente la sede leonesa, son presentados como víctimas que luchan en defensa del patrimonio episcopal amenazado en diversos frentes. No se suceden directamente pues Pedro es depuesto y expulsado por el rey Alfonso de Aragón junto con otros obispos en 1111 y usurpada la sede por el arzobispo Mauricio de Braga, hasta que aparece Diego como obispo hacia 1113. Este obispo es presentado, en cierta medida, como el gran restaurador y reorganizador del patrimonio episcopal, como los textos comentados podrían probar a los que suelen añadirse otros dos de gran importancia, uno de 1116 por el que hace donación solemne a la catedral de muchos bienes e iglesias recuperados y otro de 1120 que parece la primera separación entre mesa episcopal y capitular, fijando las prebendas de los canónigos para evitar los males derivados de formas de gestión anteriores. De este modo, la imagen que ha quedado de este prelado es la de gran seguidor de la reforma eclesiástica en León. Es cierto que a tío y sobrino se les consideraba partidarios de la reina Urraca en el conflicto 
bélico, y también se aludía a los problemas para la sede leonesa derivados de los intentos hegemónicos del arzobispo de Toledo, pero eran datos que simplemente servían para ilustrar la crisis sufrida por el episcopado en esos años ${ }^{27}$.

Recientemente los inteligentes comentarios de Fernández Catón a su edición del fondo catedralicio ${ }^{28}$, permiten cuestionar esta visión positivista al señalar algunos aspectos que, en mi opinión, muestran esa necesidad, ya apuntada en otro lugar ${ }^{29}$, de indagar en la red de relaciones interna y externa que los miembros de una institución, mantenían, generaban o en las que se incluían. Un documento de 1122 contiene información muy rica al respecto por lo que, aunque muy brevemente, he de comentarlo aqui. Se trata de una karta deffinicionis al obispo Diego, no a la iglesia, y a su familia (fratribus et sororis uestris), que hace Urraca gracia Dei regina Hyspanie, título dado por el notario real que es el que la redacta. Carta que al final se expresa como concordiam pacis et deffinicionem de omnibus malis que usque nunc inter nos fuerunt. Dato éste que muestra las alianzas entre la reina y el obispo tan contingentes y cambiantes, como lo habian sido las de su tío Pedro ${ }^{30}$. Entre la concesión con inmunidad de una heredad de realengo que la reina le concede en 1113 pro bono et fideli servicio que michi fecistis et quotidie facitis y el diploma de $\mathbf{1 1 2 2}$ han debido ocurrir algunos hechos que la narración que este último contiene interpretada positivamente no va aclararnos. Veámos, la reina manifiesta que ante ella, Diego con sus hermanos y hermanas, han sido acusados por sus inimici de haber recibido la mayor parte de las limosnas que su padre el rey Alfonso había donado a su auunculus el obispo Pedro para que distribuyera entre las iglesias, pobres y clérigos tam de Ispania quam ultra portos. Es así como se razona la decisión de la reina de haber mandado prender (iussi capi) a la hermana del obispo Diego, María Euláliz y al marido de ésta Aznar Cipríaniz y obligarles a pagar seis mil sueldos que promete no volver a reclamarles.

27 VILLACORTA, T., El Cabildo Catedral de León. Estudio histórico-jurídico, siglos XI-XIX, León, 1974 (págs. 36-38); FLETCHER, R., The episcopate in the Kingdom of Leon in the Twelfth Century, Oxford, 1978 (págs. 68-69). Documentos citados: 1116/CL, 1351; 1120/CL, 1367.

${ }_{28}$ Tales comentarios en el t. $V$ de la colección citada en $n$. 5 , principalmente en los documentos 1333,1343 y 1370.

29 Alfonso, J., «La comunidad campesina», pág. 317 en PAStor, R., Alfonso, I., Rodriguez, A., SÁnCheZ, P., Poder monástico y grupos domésticos en la Galicia Foral (siglos XII-XNV). La Casa. La Comunidad. CSIC, Madrid, 1990.

30 A Urraca, siendo infanta, hizo grandem calupniam y grandem querellam el obispo Pedro porque se llevaba los villanos y heredades de la iglesia de León reclamándole éstas. Alfonso VI para dirimir el caso y solucionar la grandem confusionem el grandem baraliam de regno suo prohibió las tranferencias entre los diferentes señoríos conocidos (1089/CL,1244). Nótese la fecha, pues a medida que se reune más información, pareceria que el periodo de crisis de fines del xı y principios del XII tendría que ser ampliado. Para un comentario muy detallado y matizado de este documento ver EsTEPA, C., «Formación y consolidación», págs. 2Q6-207.

Hispania, LVII/3, núm. 197 (1997) 917-955 
Sigue después el ritual de generosidad y misericordia acostumbrado por el que la reina les perdona su malam uoluntatem, les recibe en León y les restituye sus casas $y$, junto con los canónigos -que aparecen por primera vez en el relato--, autoriza al obispo para que en vez del censum deffinitum que debía por sus arcedianos y hermanos entregue $a b$ altare gloriosisime regine una tabulam argenteam y unam kalsam auream ${ }^{31}$ por lo que la reina dona dos villas que completan la concordia.

Claramente, este texto refleja tensiones que afectan a la sede leonesa más complejas de las que recoge el argumento tradicional, que se formalizan en torno al mal uso de una limosna regia que aun importante no es sino la estrategia legitimada para articular conflictos más profundos. Nótese como la reina se hace eco de acusaciones de los que define como enemigos de la parte juzgada, forma de aliarse con ellos en un juicio en el que parece actuar como juez y parte. Que entre estos enemigos figuren los canónigos no debe extrañarnos si entendemos que el problema de fondo que se está debatiendo no es otro que el de la distribución y asignación de los recursos eclesiásticos de la catedral. Y éste no es un problema meramente interno como indican las parentelas episcopales implicadas. De este modo la generosa y amplia donación que el obispo Diego hace en 1116 a la iglesia de León para remediar la caótica situación en la que se encuentra como retóricamente dice, y las disposiciones de 1120 fijando y concediendo autonomía económica a las canongías, no pueden ser interpretadas como meras reorganizaciones administrativas de un obispo reformador sino que deben ser entendidas dentro de este contexto de lucha por la tierra y el poder que conlleva, en un ámbito que no es puramente institucional. En realidad, si nos fijamos un poco más vemos, que la donación de 1116 por quien se titula obispo diuina disposicione, se hace a los canónigos, no a la catedral (dono canonicis eiusdem canonice), y que no son sus bienes propios los que dona sino los pertenecientes a un arcedianato. Sin duda, es éste otro episodio de la misma contienda, cuya trama relacional queda muy bien expresada en el preámbulo del texto que el obispo Diego ha de realizar para dar satisfacción a los canónigos. Allí motiva su decisión en el intento de evitar la iniustitiam et controuersiam que tiene lugar al depender las prebendas que éstos reciben de la voluntad del prelado condicionada prout amicicia, seruicium, amor sui generis, uel ira, et odium, en vez de ser asignadas sicuti santi canones.

Sin pretender extenderme sobre estas cuestiones que merecen estudio más detenido hay que decir que el obispo Diego Euláliz, al que nos estamos refiriendo, se muestra en esos años activo constructor de un patrimonio particular-familiar en la Valdoncina, lugar del que debe ser originario, para el que consigue sucesivos privilegios de inmunidad de la reina Urraca en 1113 y de Alfonso VII en 1129 - que le convierten en un coto señorial

31 Este punto no queda totalmente claro en este documento pero pienso puede interpretarse así por la lectura del siguiente, CL,1370, donde se repite esta transacción.

Hispania, LVIU/3, núm. 197 (1997) 917-955 
importante ${ }^{32}-$. El emperador dice hacer la concesión atendiendo a los ruegos de los amigos de dicho obispo entre los que están los condes Suero Vermúdez y Rodrigo Martínez y otros nobles importantes, dato que nos revela la amplia y densa red de relaciones sociales en la que hemos de entender todas estas acciones ${ }^{33}$. Se dibuja así un campo de tensiones, una estructura conflictiva latente si asumimos la expresion de Geary ${ }^{34}$, que afecta al tejido de relaciones interno de la institución ecclesiástica que tiende a dotarse de normas que regulen sus relaciones como una de las formas de prevenir, encauzar y solucionar esos conflictos ${ }^{35}$. Sin embargo, ha de quedar claro que esta estructura de relaciones resultará incomprensible si no la pensamos en conexión con otras redes exteriores. La catedral como institución es un recurso no sólo de sus miembros, sino de otros grupos sociales, incluídos los reyes, que de muy diversos modos y en grados muy diferentes tienen expectativas y quieren participar de sus bienes materiales tanto como de los inmateriales.

Para la comprensión que estamos planteando uno de los datos de mayor interés es comprobar como alguno de los infanzones citados en 1093, ellos o sus hijos, vuelven a aparecer en 1115 ó 1117, siendo éste uno de lo elementos que permiten asimilar el estatus social de los protagonistas de unas y otras disputas y establecer relaciones entre ellos. Así, Rodrigo Cipríaniz pleitea en 1093, junto con los que deben ser sus tres hermanos, Alvaro, Domingo y Aznar, pues llevan el mismo apellido y sus nombres se copian seguidos en el documento ${ }^{36}$; sus hijos disputan en 1117 junto con los de Pedro Sarracínez y el mismo obispo, a ellos se les reconocerá la mitad del monasterio de San Tirso. En 1093 disputan dos Martín Citiz con el mismo nombre, uno que se dice de Villa Albura y el otro de Villaseca; los hijos de uno de ellos están también entre los que litigan por San Tirso en 1117 junto con Pelayo Froilaz y sus hermanos ${ }^{37}$. Los hijos de Miguel Rodríguez a quien vemos pleitear con su

32 El realengo que recibe de la reina Utraca en 1113 en Santovenia de Valdoncina, es delimitado por los términos de otras villas sobre las que en años sucesivos prosigue su expansión, y eximido de omnem regalem calumniam, penando a todo el que sine uestra iussione intrauerit audaciter. La inmunidad que concede Alfonso VII en 1129 es a la villa de Antimio que el obispo ha ido integrando en su patrimonio particular mediante compras y permutas durante esos años $(1113 / \mathrm{CL}, 1343 ; 1116 / \mathrm{CL}, 1353 ; 1117 / \mathrm{CL}, 1357 ; 1123 / \mathrm{CL}, 1379 ; 1129 / \mathrm{CL}, 1387 ; 1129 / \mathrm{CL}, 1389)$

${ }_{33}$ Alfonso VII dice dice hoc autem facio uestro amore, et interuentu uestrorum amicorum. comitum... 1129/CL,1389.

${ }^{34}$ GearY, P., «Vivre en conflict...»

$351120 / \mathrm{CL}, 1367$.

36 Alvar y Rodrigo Ciprianiz aparecen también confirmando juntos en un documento de la catedral de León (1097/CL,1300)

37 Uno de éstos Martin Citiz pienso es el que en 1060 confirma, junto con Trasmiro Fortes, otro de los litigantes, una venta de Fáfila Petríz (1060/Carrizo,2); Tal vez sea el mismo que en 1106 hace una importante donación a Sahagún. Más que los lugares donde dona, su identidad puede ser deducida del grupo con el aparece confirmando: Pedro y Ordoño Sarracínez, Pelayo Vellitiz, los Nebzaniz entre otros.

Hispania, LVIV/3, núm. 197 (1997) 917-955 
padre en 1115 aparecen sin éste en 1117 junto con Pedro Vermúdez y sus hermanos.

Pero de mayor interés es identificar el contenido de este estatus de infanzonía que se les reconoce. De 1093, conocemos la identidad de dos de ellos. Uno es Cipriano Vellitiz, litigante en ese año junto con sus sobrinos y consanguíneos. Su importancia viene dada por el hecho de ser hermano de Pelayo Vellitiz un importante personaje de la corte de Alfonso VI y a él mismo le hemos visto en 1067 como uno de los testigos de apoyo del obispo anterior don Pelayo frente a las pretensiones de Havive Donniniz sobre la villa de Cimanes ${ }^{38}$. El otro es Aznar Cipríaniz que junto con sus hermanos protagoniza los sucesos de 1093. Su matrimonio con Maria Euláliz, sobrina, como hemos visto, del obispo Pedro con el que se enfrentan, da otro cariz al litigio, incluso si la alianza matrimonial es posterior a estos hechos, pues les hemos visto aparecer implicados en la posesión ilegal de bienes catedralicios en connivencia con su sucesor en la sede, Diego, durante cuyo episcopado se desarrollan los otros enfrentamientos. Esto puede explicar que en 1117, los sobrinos de Aznar aparezcan del lado del obispo, cuñado de su tío, en el reparto de la mitad del monasterio disputado. Son pues, estos datos los que permiten plantear y señalar algunas líneas de conexión entre conflictos diferentes.

De 1117 conocemos un poco más la identidad de otros tres hereditarii, como se les denomina entonces. Uno es Pedro Sarracínez, al que hemos visto después de la disputa con Sahagún por Villacorta quedar como concesionario de algunos bienes monásticos, sus hijos son los que ahora intervienen junto con los hijos de Rodrigo Cipríaniz. El otro es Pelayo Froilaz quien con sus hermanos figura entre los herederos a los que se reconoce la otra mitad de San Tirso. La información contenida en el cartulario de Carrizo permite identificarlo como uno de los nobles más poderosos en este área del Bernesga, que es el territorio de Luna donde ha ido formando un patrimonio importante. Pienso que es uno de los hermanos del magnate Ramiro Froilaz junto al que aparece en 1105 y, por tanto, hijo del conde Froila Diez, filiación avalada por el hecho de que su "archivo» pase al monasterio de Carrizo, la fundación de su sobrina Estefanía Ramírez en la segunda mitad del siglo XII, como ocurrió con el de sus parientes los Flaínez recogido en el suyo de Otero de Dueñas. No es lugar para indagar más acerca de este noble que figura en el séquito del poderoso conde asturiano Suero Vermúdez, sin embargo, no carece de interés notar que entre las referencias de autoridad de los docu-

38 Vid pág. 923. Su relación familiar entre otros datos pienso puede confirmarse por una donación a Sahagún de lo que tenía de Pelayo Vellitiz en el Valderaduey, a excepción del solar de Cipriano Vellitiz. Sobre Pelayo e Isidoro Vellitiz, a quienes considera caballeros locales en la zona de Torozos, escribe Reglero, C., Señoríos. págs. 99-100, sin embargo, pienso que en este caso, como en muchos otros de los que estamos tratando, debemos ser precavidos sobre «cómo de local es esta nobleza local», problema que ya planteabamos en nuestro trabajo colectivo «Baja nobleza: aproximación a la historiografia europea y propuestas para una investigacións, Historia social, 120, 1994. 
mentos en los que interviene entre 1112 y 1123, el obispo Diego de León sólo aparezca en dos, 1114 y en 1119, reflejo posiblemente de las hostilidades y problemas de esos años ${ }^{39}$.

Otro noble conocido de 1117 es Pedro Vermudez que interviene en la disputa con sus hermanos y con los hijos de Miguel Rodríguez, que tal vez están entre los innombrados de 1115 . Su escasa aparición en la curia regia hace que Estepa le considere un noble local ${ }^{40}$. Pienso que es el mismo al que Alfonso VI expulsó del reino por sus malfetrías y le confiscó bienes que en 1097 entrega a la Catedral de León. Esto le haría hijo de Vermudo Eriz, nieto de Ero Salitez, nobles de un nivel pienso similar al Froilaz anterior para los que el término de local sin duda les queda un poco pequeño ${ }^{41}$.

Sería de interés entender el tipo de agrupaciones que en este texto se distinguen, cuáles son los criterios que los dividen por mitades, a unos con el obispo y a otros separadamente, tal vez debidas al proceso mismo por el que se han hecho hereditarios e indicio de las diferentes vinculaciones que han desarrollado. Lo que parece quedar claro es que los infanzones que se enfrentan a los obispos de León son o al menos entre ellos hay gentes a las que habría que otorgar un estatus de nobleza media, vinculados familiar o clientelarmente a la nobleza magnaticia y próximos a la realeza, con recursos eco. nómicos autónomos, es posible que ellos sean los aglutinadores de estas acciones que concentran a infanzones de más bajo estatus y a los notables de las comunidades campesinas. La escasos datos con que contamos apuntan a que las relaciones entre ellos no difieren mucho de las que mantienen las instituciones eclesiásticas con sus vasallos laicos.

Poquísima información tenemos para profundizar en el análisis de las relaciones entre nobleza laica y eclesiástica, pero si la suficiente para plantear algunas cuestiones, ya adelantadas antes, que pienso deben formar parte activa ${ }^{42}$ del contexto de reflexión que propongo. En estos pleitos tenemos colectivos de infanzones acosando y violentando el patrimonio de la catedral

39 A principios del siglo xu incrementa su patrimonio notablemente y de forma continuada en esa zona. Documentos del monasterio de Carrizo, 4, 5, 6, 7, 8, 11, 12, 13, 14, 15, 16, 17, 18 , $19,20,21,22,23,24,25,26,27$ en CASADO, M. C., Colección diplomática de Carrizo, I, León, 1983. S. Barton comenta y traza el mapa de su patrimonio en su reciente libro The Aristocracy in Twelfth-Century Leon and Castille, Cambridge, 1997 págs. 73-79, le considera si no magnate si en un circulo muy influyente, el de la clientela del conde Suero Vermúdez, detentador de las tenencias de esta zona durante el periodo. Sin embargo, no parece establecer su filiación del conde Froila Diez.

40 Estructura, pág. 286.

41 Sobre Pedro Vermúdez documentos de CL, 1293, 1346, 1357, 1389, 1405, 1406 y 1407. Sobre los Eriz vid. REGLERO, C., Señoríos, págs. 87-91. Vid. también supra n. 38 para los problemas de delimitar la noción de localidad.

42 Digo parte activa de modo explicito, porque quiero cuestionar un fenómeno muy frecuente, consistente en señalar aspectos muy complejos de relaciones en la materia que se esta tratando y obviarlos como elemento activo a la hora de realizar algún típo de conclusiones, con el resultado de interpretaciones a veces mixtificadoras.

Hispania, LVII/3, nim. 197 (1997) 917-955 
de León, es decir los ingredientes habituales que justifican hablar de Iglesia/Nobleza enfrentada. Hemos comentado, sin embargo, algunos datos que cuestionan interpretación tan simplista. La información, tan rara de encontrar es cierto aunque probablemente menos de lo que suponemos, acerca del parentesco entre uno de los infanzones y los prelados, de lá mezcla de intereses particulares e institucionales que se detectan, de la sucesión en la sede del tío por el sobrino, nos previenen de "reificar" las instituciones del tipo que sean y estimula a indagar en esta línea atendiendo a la red de relaciones personales interna y externa que generan o en las que están inmersas. El difícil estudio de la procedencia social de los eclesiásticos debería ser ampliado al de las conexiones que mantienen con sus redes parentelares y sociales laicas. En este caso se podría aventurar sin demasiado riesgo los lazos e intereses entrecruzados que sin duda existieron entre canónigos e infanzones. Pues, por otro lado, observamos los vínculos clientelares que se dan entre estos nobles y la catedral en una relación, muy bien calificada por Reuter como simbiótica, cuyas condiciones han de ser renegociadas periodicamente ${ }^{43}$. El pacto de 1117 por el que estos nobles quedan como defensores del patrimonio monástico que se comprometen ampliar y del que compartirán los beneficios es muy claro en este sentido, y similar a los que repetidamente encontramos en la documentación de todos estos siglos. Se especifica que ipsi hereditarii semper auxilientur suis rebus...et defendant pro posse suo, et amplificent illud monasterium suis hereditatibus. Esta defensa frente a otros poderosos y en las relaciones con los productores campesinos es, en definitiva, la que permite el ejercicio del dominio eclesiástico. Además, se explicitan algunas de las funciones que cumplian las instituciones religiosas para sus propietarios o patronos laicos. Cualquiera de estos infanzones pertransiens in monasterio hospitari uoluerit, recipiatur sicut hereditarius o si ad inopiam deuenerit, atque in monasaterio morari et ibidem Deo deseruire uoluerit, recipiatur et honeste tenatur pro posse abbatis qui eo tempore monasterio prefuerit ${ }^{44}$.

Que la lucha sea, explícitamente en el primer caso de los analizados, por hereditates, uillas et homines no supone que los poderosos laicos se impongan sólo por la fuerza y la violencia como suelen alegar sus contrincantes eclesiásticos y no busquen como ellos vías que legitimen su dominación real o pretendida, dominical o puramente señorial. Aquí quiero poner de relieve el tipo variado de relaciones y dependencias que el uso de la tierra

43 Sobre conflictos dentro de la red episcopal Vid. REUTER, T., “"Filii matris nostrae pugnant adversum nos": Bonds and Tensions between Prelates and their milites in the German Higth Middle Ages» en Chiesa e mondo feudale ne secoli $x$-x/l, Milano, 1995, págs, 247-276; PASCUA, E., «Redes personales y conflicto social: Santiago de Compostela en tiempos de Diego Gelmírezm en Hispania, 185 (1993), págs. 1069-1089, uno de los mejores trabajos que he leido sobre estos tipo de análisis. Sobre esta interrelación entre nobleza laica y eclesiástica es útil también BouCHARD, C., Sword, Miter, and cloister: Nobility and the Church in Burgundy (980-1198). Ithaca, 1987.

44 Sobre las funciones de los monasterios para sus propietarios o patronos laicos vid. los trabajos citados en nota núm. 3 .

Hispania, LVIl/3, núm. 197 (1997) 917-955 
permite, uso cuyo control, propietario o señorial, es el que en última instancia se disputa.

En el discurso eclesiástico contenido en la narración de estos litigios destacan términos como los usados en el documento de 1093: introierunt. uiolentia militum amiserunt o uim rapuerunt a través de los cuales y de otros que amplian el campo semántico de la violencia nobiliaria, los monjes van construyendo esa imagen de sus enemigos que ha servido igualmente a muchos historiadores para construir su modelo de dominación señorial.

Sin embargo, este texto permite observar igualmente formas más pacíficas de relación entre nobles laicos y campesinos, vías menos violentas de acceder a sus tierras, que se declaran ilegítimas o simplemente se prohíben por los que se pretenden sus dueños. Son estas las que ahora quiero destacar. Por compras se dice habían ido adquiriendo los infanzones y sus antepasados muchos de los bienes de las gentes de esas villas de la ribera del Bernesga, cuyo precio les es devuelto para que los abandonen y se comprometan a no volver a adquirirlos. Pero además esos milites habían estado recibiendo en sus heredades a los hombres del obispo, ahora se les exige no hacerlo excepto con jóvenes, niños y doncellas que sean excusados, con la obligación de que retornen a sus casas a la muerte de sus padres si no quieren perder las heredades de éstos. El obispo, al igual que sus colegas eclesiásticas las monjas del monasterio de San Pedro de Dueñas años más tarde, parece consciente de los peligros que para el ejercicio legítimo y efectivo de su dominio entrañan esas alianzas entre la nobleza de caballeros y los campesinos de las villas en las que comparten algún tipo de poder. De ahí sus intentos de controlarlas a través del control de las transacciones de tierras ${ }^{45}$.

Veámos ahora los procedimientos de resolución judicial de estos litigios que son las que pretenden recoger los documentos que analizamos. Los argumentos esgrimidos por las partes en los tres casos se refieren a derechos de propiedad contrapuestos y a las formas legitimadas de adquirirlos. En 1093 hemos visto al obispo acusar a los infanzones y a sus antepasados de haberse apropiado de bienes que habían sido donados por los reyes a la iglesia, de poseerlos por tanto injustamente; hemos visto también a los infanzones defenderse alegando que habían sido obtenidos por sus padres y abuelos. La ambigüedad de los términos utilizados - tenere, possessionem, aforastitisdificulta saber si es la tenencia o la propiedad lo que se está debatiendo. En cierta medida, por las alegaciones del obispo y por la resolución final parecería que los infanzones, a los que podemos suponer con propiedades y tenencias antiguas en esas villas, han ido ampliando las primeras mediante compras a los vasallos de la catedral y negando las segundas a través de la

45 Sobre estos problemas y comentarios de este documento en ALFonso, I., «Campesinado y Derecho: la vía legal de su lucha» en Noticiario de Historia Agraria, 13 (1997) págs. 24-26.

Hispunic. LVII/3, nu்m. 197 (1997) 917-955 
separación a que se refiere el prelado. Es posible igualmente, como sabemos por otros litigios que las dos partes estén pretendiendo el poder señorial sobre los hombres de esas villas. En cualquier caso, el carácter fragmentado tanto de la propiedad como del poder que conlleva, que viene de antiguo y no soluciona el conflicto, constituye componente principal de estos antagonismos. En 1115 y 1117 las pretensiones sobre el monasterio de San Tirso (sus heredades y villas e implícitamente sobre los hombres que las habitan) se articulan con argumentos similares y las soluciones, en última instancia, consagraran igualmente la fragmentación de derechos.

El primer caso es llevado ante la presencia de Alfonso VI, por exigencia de los infanzones, quienes manifiestan que solo obedecerán el juicio y decisión del monarca. La pesquisa es el método utilizado para averiguar la verdad de las demandas de unos y otros. No conocemos ni la forma ni los medios utilizados para realizarla, tampoco su contenido que, sin embargo, podemos deducir de la resolución regia de entregar al obispo, a través del portero de su palacio, todo lo que la iglesia por negligencia o violencia de los caballeros había perdido. Justicia y adjudicación regia alcanzadas, en esta disputa entre nobles, a través del método de prueba asumido como el más racional, es rechazada por los perdedores, ahora calificados como milites regis, que logran reabrir o continuar el proceso. Las estrategias de los infanzones parecen frustrarse ante la prueba propuesta por el rey de que tres clérigos de la catedral ratifiquen los juramentos de la pesquisa, por lo que nuevamente deciden cambiar de táctica, y solicitar la misericordia del obispo reconociéndose culpables. No hay castigo ni pena. El resultado es la larga convenientia a la que ya nos hemos referido. $Y$ hay que preguntarse incluso, en que medida se hizo efectiva si eran ellos los implicados en mantenerla. Todas las garantías del proceso indican las dificultades en este sentido.

Los procedimientos para resolver los litigios que les enfrentan difieren en los dos casos posteriores. En el de 1115, hay una referencia explícita a un momento anterior muy inmediato en el que el desacuerdo respecto a la propiedad del monasterio, que ambas partes alegaban como suya, había provocado la usurpación violenta de los milites y la respuesta episcopal de excomunión. No sabemos si todo el proceso tiene lugar en el concilio donde el placitum es of́do y confirmado, y desconocemos la naturaleza de esta asamblea. En cualquier caso, el obispo hubo de publicitar su excomunión y las violencias debieron estar en boca de todos. Se repiten, como hemos visto, rituales de sumisión y devolución de bienes y de misericordia y perdón. Ahora la disputa aparece como más local, cada parte utilizando sus armas, los milites la violencia, el obispo la excomunión. En la renuncia se comprueba que eran hereditarios, tenían raciones en el monasterio disputado. En este momento la derrota de los infanzones parece completa, la espada espiritual (gladio anathematis) se muestra tan efectiva como las que ellos usaban.

La reapertura del litigio en 1117 servirá, sin embargo, para matizar esta victoria. En realidad, los infanzones parece han continuando detentando en la práctica las heredades monásticas, que acuerdan devolver, a cambio de que ahora se les reconozca como herederos en el mismo. De este modo, aunque se 
establece la hegemonía episcopal ellos obtendrán ventajas también, al igual que el obispo, unos y otro mutuamente necesarios, frente a otros infanzones, frente o junto con los campesinos. Las garantías del pacto en este caso, a diferencia de lo que es usual, obligan a ambas partes, $500 \mathrm{sl}$., sin penas espirituales. Es el acuerdo largo tiempo perseguido en el que quedan vinculados, el método más eficaz de cumplimiento.

El rey no vuelve aparecer y la comunidad política gestiona sus propios asuntos en sus asambleas, con la presión de unos y otros, no son ni más violentos ni más paćficos ahora que antes. En uno y otro caso parecen predominar e imponerse las relaciones de fuerza locales incluso frente al mismo rey como vimos en 1093. La dinámica es cambiante, contingente y ellos lo saben de ahí el énfasis que ponen en establecer pactos y estabilidad firmísima, porque no ignoran lo precario de la misma. No se vence o pierde completamente, se disputa, negocia, pacta reparto y gestión de intereses comunes. Es la misma política esta manipulación de recursos con los que cuentan, a través de los que gestionan su propia reproducción como tales.

La renovación de relaciones que resulta de este tipo de acuerdos vemos cómo es heredada y negociada por los descendientes. Esta es la situación de Pedro Sarracínez, al que hemos dejado páginas atrás como tenente de Sahagún después de una de estas reclamaciones y cuyos hijos han quedado en situación similar respecto a la Catedral de León. Prosigamos ahora con algunos miembros de su familia. Una vinculación más estrecha con el gran cenobio leonés es la que establecen su hermano Ordoño Sarracinez y la mujer de éste Fronilde Ovéquiz, quienes a principios del siglo XII deciden su entrada en religión, uno en Sahagún y la otra en San Pedro de Dueñas. Las negociaciones que hacen entre sí y con los hijos de ella, habidos en matrimonios anteriores, sobre la disposición de sus bienes en ese momento nos ponen en relación con otro tipo de problemas en mi opinión íntimamente conectados con los que venimos comentando, aunque las conexiones en muy pocas ocasiones se nos revelen claramente, de ahí la importancia de tenerlas en cuenta. Me refiero a los conflictos y disputas que podemos denominar intrafamiliares", o "intraparentelares» si no queremos cargar con las dificultades que la noción "familia" entraña.

De Fronilde sabemos se ve envuelta en varios de estos conflictos a los que simplemente aludiremos ${ }^{46}$. Conocemos una temprana querella que hace contra su propio padre por sentirse desheredada de la tercia de sus bienes en favor de la madre, que presenta ante sus gentes y multos homines bonos reunidos para dilucidar esta causa en la fundación familiar de San Salvador de Villacete, que resuelven en su contra. Muchos años después esta mujer, que

46 Soy deudora en lo que sigue del cuadro sobre esta familia que traza MARTínEz SOPENA, P., al hablar del caballero local Pedro Peláez de Arnales, uno de sus descendientes (Tierra de Campos, págs. 405-410)

Hispania, LVH/3, núm. 197 (1997) 917-955 
hacia 1103 había decidido de acuerdo con su marido hacerse monja y entregar los bienes negociados con éste y sus propios hijos con el fin explícito de evitar sus reclamaciones, se ve de nuevo juzgada, y esta vez excomulgada, por un tribunal eclesiástico debido a la ruptura de su compromiso religioso y al hecho de haberse acogido al patronazgo de un noble laico con todas sus heredades ${ }^{47}$.

No es el momento de analizar más detenidamente los problemas de esta noble que requieren más largo estudio, he aludido a ellos porque muestran otra de las líneas básicas de tensión que suele quedar obviada historiográficamente al presuponer solidaridad natural a las unidades familiares o grupos parentelares. Es necesario prestar más atención a las tensiones que la asignación y distribución de recursos, y su ritmo temporal, en el seno de los grupos familiares, sin duda, conlleva. La disposición de parte de estos recursos en favor de instituciones religiosas, uno de los actos más y mejor documentados, como todos sabemos, de la edad media occidental, forma parte de un mismo proceso de reproducción material y social de los grupos implicados. Las reclamaciones y disputas por la tierra frecuentemente legitimadas por los laicos como demandas hereditarias pueden ser vistas entonces, no tanto como meros intentos de reconstrucción de patrimonios fragmentados por liberalidades familiares anteriores, respondiendo a un presunto derecho de retomo que preservaba los patrimonios familiares, sino también como medios para afirmar explícitamente tal herencia, como estrategias para participar en los beneficios que tal vinculación implicaba, o como forma de cuestionarla y renegociarla ${ }^{48}$ tal como estamos proponiendo en estas páginas.

Es esta dinámica de donaciones, acoso y ocupación violenta, renuncia y defensa de bienes monásticos sobre los se ha tenido alguna disposición hereditaria la que subyace igualmente a algunas de las actuaciones de las que tenemos noticia protagonizadas por descendientes de Fronilde Ovéquiz. Sus nietos, Bermundo y Pelayo Pérez, aparecen donando en 1135 al obispo de Astorga para reparar las violencias cometidas en monasterios de su diócesis a los que están vinculados 49 . Un sobrino nieto, Fernando Díaz, en 1129 disputa con el monasterio de Vega y renuncia a omne ius et omnem querelam quam petebam en Valdespino, recibiéndola en tenencia durante su vida. En esa villa el abuelo, Pedro Ovéquiz, había donado su divisa al monasterio de Sahagún en 1048 y él mismo habia dado a Vega la mitad de su heredad en $1113^{50}$.

La mayor información que se conserva de su bisnieto Pedro Peláez de Arnales, ha permitido como decía antes, a Martínez Sopena trazar la historia familiar y patrimonial de este caballero local de la que tomo estos datos y utilizo para contextualizar mis comentarios. Tenente de Villafrechos, villa en la que ya su bisabuela había donado bienes a Sahagún, donde sigue teniendo

47 Los documentos citados: 1059/SHG, 424; 1103/SHG, 1091, 1092, 1093 y 1094; $1115 /$ SHG, 1192.

48 WhITE, S., Laudatio, págs. 167-190.

49 Información citada por MaRTinez SoPENA, P., Tierra de Campos, pág. 407.

50 Serrano, L., Cartulario del monasterio de Vega, Madrid, 1927, documentos: 19, 28, 34 y 36. 
propiedades su abuelo, que entrega a la catedral de Astorga y en la que él mismo continua como potente hacendado, además de en zonas próximas de Tierra de Campos. Figura en el séquito de Fernando II y vinculado estrechamente a Sahagún, especialmente a través del que fuera monasterio familiar de San Salvador de Villacete, sobre el que, aun convertido en priorato del primero, sigue ejerciendo su patronazgo, consiguiendo que dicho monasterio en la práctica permanezca como recurso institucional de su linaje -panteón familiar, institución de ayuda y reserva económica-. Le vemos titularse señor del mismo junto con el prior y tres monjes, cuando en 1197 conceden a su nieto Pelayo Núñez la heredad de ese monasterio en Coreses en las condiciones acostumbradas de tenencia vitalicia y devolución con lo incrementado a su muerte, además de la obligación en este caso de recibir al prior y a los monjes de Sahagún cuando vayan a la villa ${ }^{5 !}$.

Aunque Pedro Peláez no parece protagonizar disputas judiciales la documentación conservada, que lo muestra como activo negociador de su patrimonio en el seno familiar y en relación con los monasterios con los que se vincula, deja traslucir que las tensiones, más o menos abiertas, no debieron estar ausentes. La terminología usada en esta documentación permite deducirlas. La carta unitatis y bona amore que hace en 1185 con su mujer y las diferentes convenientia con sus hijas y yernos, con su hijo abad de San Pedro de Montes y con su nieto, entre 1189 y 1194 , en las que se contienen minuciosas y cambiantes disposiciones patrimoniales, muestran los problemas y dificultades que el reparto hereditario implicaba y las negociaciones necesarias para consensuarlo. El hecho de que todos esos diplomas sean realizados ante concejos de diferentes villas revela, además de la amplitud del patrimonio, la importancia que se da a la publicidad de esos actos. Igualmente, la conventionem que firma con Sahagún en 1176, que supone ratificar su amplio control sobre el de Villacete a pesar, o porque cede la porción que todavía conservaba en el mismo, con cláusulas de mutuo beneficio que le vinculan estrecharnente al primero, pudo finalizar uno de esos momentos conflictivos a que me estoy refiriendo. Que hubo otros nos lo revela una donación que hace en 1192 por la que además de entregar toda su heredad y divisa en Cañizo, confirma su porción en el monasterio de Villacete y devuelve dos iglesias que a éste pertenecían, confesando que una de ellas per uiolenciam inuasimus e iniuste possedimus, percibiendo, a través del clérigo puesto por él, los diezmos, primicias y oblaciones debidas por los vasallos del prior y monjes del monasterio. Es posible que tanto la donación como la confesión sean resultado de un proceso judicial, pero también pueden ser un simple acuerdo directo o mediado que termina con disputas anteriores. Llama la atención de todas estas acciones la multitud de transacciones que son posibles y se hacen con unos mismos bienes, hecho que ha llevado a plantear a muchos autores si estas donaciones realmente tuvieron lugar en la práctica.

51 Los documentos citados: SHG, 1388, 1416, 1420, 1428, 1466, 1465, 1484, 1485, 1511, 1512, 1513,1516

Hispania, LVY/3, núm. 197 (1997) 917-955 
De fines del siglo XII y principios del XIII se documentan también acuerdos que realizan gentes próximas a los anteriores con el mismo monasterio de Villacete, que nos informan mejor de los procedimientos de resolución a través de los que se han alcanzado. En 1199 Fernando Petri ${ }^{52}$, hace convenientia con el prior de dicho monasterio coram bonis hominibus de Uillardiga et de Cannizo sobre la heredad del primer lugar que confiesa ego per forciam et per meos parentes uolebam extorquere ut nequa quam eam haberet domus de San Salvador. Los argumentos se repiten justificando m'ejor, si cabe, la fuerza utilizada, motivándola racionalmente talis erat mea racio - dice- que la heredad fuerat patris meis que la había obtenido del monasterio tali convenientia: ut esset amicus et familiaris domus Sancti Saluadoris semper y que fuese enterrado alli como hizo, que tuviese la heredad recibida vitaliciamente y que la transmitiera a este hijo, y que en caso de incumplimiento por el monasterio tendría que recibir otra heredad. Todo esto -continua relatando- el dominus prior dextruebat et nequaquam dicebant esse uerum, set falsum. Pero ahora Fernando Petri confiesa, remota perfidia et pace ex utraque parte reformata, abandonar su querella y no demandarlo más por remedio de su alma et pro abluendis peccatorum meorum facinoribus y para que los monjes le reciban en sus oraciones y bienes espirituales en vida y en muerte. Están presentes gentes de las dos villas afectadas, tal vez los hombres buenos ante los que se hace el acuerdo, a los que no se les reconoce intervención pero que probablemente han mediado en lograr esta resolución. Mediación más claramente explícita en la disputa que este mismo monasterio de Villacete sostiene años más tarde con Rodrigo Martínez ${ }^{53}$, militem de Tiedra, sobre una villa en Mansilla. El prior reclamaba la viña como suya y acusaba al caballero de que tanto él como su padre tenebat per forciam, acusación que éste negaba diciendo que nunca había sido así, set propria esse hereditas et ex paterno iure sibi successisse. No parece que intenten demostrar con alguna prueba sus opuestas pretensiones, lo que se consigue es reconciliacione facta per bonos homines entre las partes que uenerunt ad confecta talem: Rodrigo con el consejo de sus hermanos ofrece una tierra pequeña ubicada en terreno del monasterio, que tendría durante su vida, comprometiéndose a no perturbar más la viña disputada. Se insiste en que la convenientia fuit facta per bonos homines viéndolo y oyéndolo el concilio de Tiedra y otros muchos de Villacete. Un año más tarde un acuerdo similar cierra otra disputa que enfrentaba a este caballero con San Isidoro de León, quien después de reconocer que poseía injustamente las heredades donadas por sus padres en Pozuelo recibe en prestimonio otras cerca de Tordehumos, eligiendo enterrarse en la colegiata con la que se reconcilia.

Son éstos, me parece, buenos ejemplos del tipo de pactos que se establecen al formalizarse estas concesiones, las expectativas que se crean y la forma de

52 I191/SHG, 1530.

53 1201/SHG, 1535. Incluye MARTinez, Sopena, P., Tierra de Campos, pág. 412 entre caballeros locales de Pozuelo de la Orden. 
realizarlas si no se cumplen. Son pactos privados pero realizados públicamente en presencia de sus iguales los hombres buenos de estas villas, reunidos probablemente en el concejo de las mismas, aunque no aparezcan con un estatus institucionalizado; el incumplimiento de las condiciones explícitas o implícitas de estos acuerdos por parte de los concedentes desata métodos y estrategias violentas, para recuperarlos, formas de presión para restablecer derechos y relaciones implicadas en los mismos. Vemos el mismo tipo de malfetrías y facinoras aludidas en otros actos, aquí asimiladas a pecados. Amistad y familiaridad siguen siendo parte de estas convenientias que son presentadas y, por tanto hemos de suponer que percibidas, como el recurso mejor para restaurar relaciones pacificas.

De este periodo otros documentos muestran igualmente las disputas a través de las que periódicamente otros caballeros negocian sus relaciones con Sahagún. De 1211 se conserva una carta donationis de la mitad de la iglesia de Valparaiso y sus heredades, realizada por Gutiérrez Díaz de Almadrán, descendiente local de los Alfonso ${ }^{54}$, con su mujer, sobrino y aliis coheredibus que pacifica (sedate et pacate) antiguas contenciones et controuersie que su padre y hermanos habían sostenido por la misma. El texto comienza haciendo pública la que puede ser considerada fórmula actualizada de una agnitio, similar a otras anteriores, es decir el reconocimiento (audivi et scio in ueritate) -no sabemos si directo o resultado de un proceso judicial ${ }^{55}$ - de cómo su padre y el con sus coheredes per iniuriam habuimus et tenuimus dicha iglesia y heredamiento hasta ese momento. En este caso la renuncia no supone sta recepción en tenencia, pero otros negocios (pacto et conuenientia) muestran la renovada vinculación entre ellos al convertirse este caballero también en defensor de los bienes monásticos que le son concedidos unos años después en prestimonio ${ }^{56}$. Los bienes que en Villavicencio recibe Sahagún de este caballero a cambio de la cesión podrían hacer pensar en un intento de desbancarle de esta villa. Sin embargo, la encomienda de toda la heredad que había sido de su padre en este lugar que, junto con otros bienes, recibe por un acuerdo del mismo tipo del que en estas fechas realiza con el monasterio de Gradefes al que vende un quiñon en Villavivencio, y su presencia posterior entre los herederos, diviseros y señores de esta villa, son signo, me parece, de la capacidad política que tienen estos caballeros, capacidad que se mantiene y reproduce en gran parte a través de este uso complejo que hacen de la tierra para establecer alianzas diversas que les permiten participar, además de en las rentas de las instituciones de las que son concesionarios, en distintas redes de poder.

Relacionados probablemente con tales formas de negociación se conservan también en el fondo de Sahagún una serie de acuerdos de la segunda

\$4 1211/SHG, 1583. Sobre su familia MARTínEZ SOPENA, P., Tierra de Campos, págs. 379-380.

55 El hecho que la carta se haga en Villapando ante autoridades y alcaldes de la villa puede ser indicativo de algún tipo de proceso judicial del que esta donación fuese resultado, pero los medios de resolución pudieron ser completamente extrajudiciales.

S6 $1216 / \mathrm{SHG}, 1603$.

Hispania, LVIl/3, nưm. 197 (1997) 917-955 
mitad del siglo XIII, por los que este monasterio recibe de gentes nobles ${ }^{57}$, numerosos bienes a cambio de la cesión vitalicia, bajo condiciones variadas, de otros. No hay referencia a ninguna tensión entre las partes pero el hecho de que se registren como pactos y avenencias, puede ser indicativo de que detrás de estos negocios hay desavenencias similares a las descritas que resuelven con acuerdos privados a los que para dar mayor firmeza y garantizar mejor, además del sello monástico solicitan sea puesto el de alguna institución con autoridad pública, como es el concejo en la generalidad de los casos ${ }^{58}$.

En la década de los setenta de este siglo xIII Sahagún vuelve a llevar sus querellas ante la autoridad regia, primero ante Alfonso X, después ante su hijo el infante Sancho. Son querellas por entramientos y tenencias forzadas de una misma villa, la de Melgar de Abajo. ¿Cómo se desarrolla ahora el proceso? ¿Qué diferencias se advierten con los documentados anteriormente? ¿Cómo podemos valorar estos conflictos ahora?.

Merece la pena un examen detenido porque permitirá averiguar el tipo de distinciones si las hubiere en los procedimientos por los que ahora se resuelven estas disputas. Lo primero que destaca son los cambios que se advierten en la forma de registrar procesos judiciales, para este pleito contamos con varios documentos y se adivina que hubo más ${ }^{59}$. Los dos primeros contienen uno, el mandato del infante Juan, que actúa por orden de su padre Alfonso X, a Pedro Pérez de Sahagún para que en servicio del rey, del que se dice es hombre, vaya a Melgar de Yuso e que sepades la uerdad de aquel heredamiento que les tenia Ferran Perez forzado; el otro, carta al concejo, alcaldes y merino del lugar donde estan dichos heredamientos para que digan verdad sobre la pesquisa y la hagan cumplir; un tercer documento informa de la entrega que manda hacer el «hombre del rey* de las heredades incautadas después de realizada la pesquisa, de la que se incluyen procedimiento de averiguación y contenido.

La información jurada proporcionada por los hombres buenos que da el concejo de Melgar y que se nombran, muestra la larga relación patrimonial en esa villa entre los ascendientes, tanto monásticos como laicos, de las partes. Sahagún según esos testimonios posef́a dos suelos antigos de tan grant tiempo que se non acordauan quanto tiempo los auien, suelos que estaban ubicados en la media uilla que heredauan dicho Fernando Pérez Ponce y sus herrnanos, con otros muchos heredamientos de viñas, tierras y huertos que también lo auian

57 La relación de algunos con las familias a que nos venimos refiriendo es clara, otros requerirían más estudio para el que no hay espacio en estas páginas.

$581253 / \mathrm{SHG}, 1718 ; 1253 / \mathrm{SHG}, 1719 ; 1253 / \mathrm{SHG}, 1720$. Tales acuerdos incorporan condiciones similares a los que se establecen después de algún tipo de disputa, por ejemplo la función defensiva y protectora que en un sentido amplio y variado se exige al concesionario es muy detallada en uno de estos pacto et conueniencia en los que se pide recuperar una de las heredades prestadas de quien la tiene en ese momento para lo que Sahagún ofrece nostro adiutorio et dando uobis uocem nostram adquirire poteritis, lo que sin duda dará lugar a conflictos entre la propia clientela monástica.

59 1277/SHG, 1813, 1814, 1815. 
de tienpo antigo. Informan después sobre otros bienes, de los avatares que recuerdan, de las transacciones realizadas entre ellos con esos bienes. La última, la donación de doña Aldonza, madre del caballero acusado, había puesto en manos del monasterio, la media villa disputada junto con el sexmo y todos sus heredamientos y molinos. Los testigos de la pesquisa dicen que esto que lo uieron heredar al monesterio e tenerlo a los sus omnes bien seys annos o mas, aunque nosotros sabemos que dicha donación, que supuso una vinculación muy estrecha y continuada con el cenobio por parte de la benefactora, había tenido lugar en $1254^{60}$. Los informantes terminan diciendo que siempre habían visto tener estos heredamientos al monasterio saluo de quatro annos aca, que gelos mando entrar don Ferran Perez Ponz por fuerça a sus merinos, que están entre los hombres buenos que informan. En estos testimonios (sabida la uerdat) se basa el hombre del rey para entregar públicamente dichas heredades a Sahagún.

Este litigio podría ser utilizado como una muestra de esa justicia más racional, objetiva y eficaz que, según la interpretación tradicional, se iría imponiendo con el fortalecimiento del poder regio y la recepción de procedimientos legales romanistas; como muestra, igualmente, de la "violencia indiscriminada» de una «nobleza levantisca», tal como suele denominarse, que en cierta medida se opondría a tales desarrollos. Sin embargo, la pesquisa, hemos comprobado, es un método judicial más habitual y anterior de lo que suele admitirse; desconocemos los argumentos del noble laico, si los hubo, pero la historia de las largas relaciones familiares con Sahagún permite deducir que la legitimación para su actuación no debió ser muy diferente de la que de forma repetida hemos venido viendo; la eficacia de la resolución, el acatamiento de la sentencia, no fueron tampoco más duraderas y estables que en épocas anteriores. Un año después los alcaldes de Mayorga han de volver a Melgar para averiguar y devolver, por mandado esta vez del infante Sancho, lo entregado a los monjes el año anterior, porque otro caballero, del que no he podido establecer la relación con el anterior, gello entro por ffuerça, esta vez sin rrazon $e$ sin derecho. Esto último implícitamente puede indicar que antes, a pesar de la fuerza, si los hubo ${ }^{61}$.

Es cierto, que el contexto en que estos hechos parecen tener lugar se ha descrito como más conflictivo, como síntoma de una agresividad nueva, más dura y grave, de los nobles y sus malfetrias, contra la gran propiedad eclesiástica ${ }^{62}$. Pero lo que estoy cuestionado precisamente en estas páginas es la novedad de estas fechorías, de estos entramientos, el que no se consideren más inherentes a los modos y formas de competición por riqueza y poder, o lo que

$601254 / \mathrm{SHG}, 1815$

61 1279/SHG, 1820;1280/SHG, 1822.

62 El trabajo clásico es el de MORETA, S., Malhechores feudales. Violencia, antagonismos y alianzas de clases en Castilla, siglos XIII-XN, Madrid, 1978, pero la interpretación de las malfetrías, los asaltos a la propiedad eclesiástica, como acciones muy particulares del período crítico de fines del siglo XIII, en relación con las cuales las instituciones monásticas se defienden entre otras formas acudiendo a los tribunales regios en busca de apoyo y mediante la concesión prestimonial primero y de encomiendas después se encuentra formulada en la mayor parte de los trabajos citados en la nota núm. 4.

Hispania, LVIL/3, núm. 197 (1997) 917-955 
es lo mismo por recursos económicos pero también políticos, entre los grupos dominantes de esta sociedad.

La complejidad del tejido patrimonial y social, la superposición de derechos, que pone de manifiesto la pesquisa anterior en la villa de Melgar, en la que diferentes señores se reparten tierras y hombres, $\mathrm{y}$ compiten por el poder sobre unas y otros, es fruto también de un complejo desarrollo político, por el que Ponce de Cabrera, bisabuelo del adversario monástico anterior, había logrado transformar la tenencia de Melgar, de la que ha desplazado a los Alfonso, en un señorío que en el primer tercio del siglo XIII se reparten varias ramas de la familia ${ }^{63}$. Proceso expansivo que ya en 1135 había enfrentado a ese conde con el monasterio de Sahagún por una heredad próxima, que el primero, con los suyos, afirmaba quod sue partis deberet esse y el abad y monjes por el contrario que sub iure de su iglesia debía permanecer secundum scripta testatorum et secundum ius ab antiquis temporibus habitum. Es un lenguaje muy jurídico, poco común en la documentación manejada, que se presenta como una resolución directa, tal vez debida al alto estatus de este noble, que entega la heredad, convencido por las racionibus et ueris eorum scriptis et auctoritatabus intellectis alegadas por los monjes, y no queriendo contradecir nec secularibus nec dituinibus legibus sino lograr salubri consensu entre los dos, insistiendo en amenazas para los que vayan contra esta justam et sanam atque verissimam et racionabilem discusión y certissiman salubremque cognitionem. Conviene señalar que esta contienda había tenido lugar pocos meses después de que Sahagún recibiera del mismo conde, tota mentis deuotione, una importante donación por la salvación de su alma y la de sus padres ${ }^{64}$.

Disputas y donaciones, violencias y acuerdos, forman el tejido sociopolítico en el que nobles laicos y religiosos interactúan, conviven y se alían como amigos, pero también se enfrentan y dañan como enemigos. Es una interacción a veces muy cercana y simbiótica, que se ve afectada por rupturas de equilibrios de poder y relaciones de fuerza, pero que parece recomponerse de forma continuada. Es evidente que la práctica es muy variada y responde a muy distintas situaciones de las que puede recoger ese esquema, pero su recurrencia a lo largo de todo el período cuestiona interpretaciones que ligan estos hechos a etapas iniciales de instituciones eclesiásticas o a las peremnes ambiciones nobiliarias. Malhechores/benefactores hay que verlos, por tanto, como dos polos posibles de una misma relación.

$$
* * \pm
$$

El contexto en el que se ha planteado este trabajo responde al propósito de entender y valorar la incidencia que en las prácticas judiciales y en las formas de acción política habían tenido los desarrollos legales y de centralización política. En los casos que se han comentado, dentro de un amplio espacio temporal entre los siglos XI y XIV, se han analizado cuidadosamente los dis-

63 Para este desarrollo bien explicado por Martinez SOPENA, P., Tierra de Campos, págs.390-92.

64 1135/SHG, 1329 y $1135 / \mathrm{SHG}, 1327$. 
tintos foros ante los que se llevaban este tipo de querellas, cómo se presentaban y argumentaban por los litigantes sus demandas, qué procedimientos se utilizaban para decidir tales casos, qué papel se otorgaba a las normas en todo el proceso, cuáles eran y qué forma tomaban las resoluciones alcanzadas. Pero es cierto que la cuestión clave que ha guiado mis reflexiones ha sido la de entender la función misma que el litigio, la forma de enfrentamiento y resolución buscada, tenía para los diferentes protagonistas, entender tambien los factores estructurales que los originaban. Recapitulemos sobre todo ésto.

Los argumentos utilizadas por las partes enfrentadas para articular sus demandas, cuando los conocemos, hernos visto que giraban en torno a dos nociones contrapuestas de propiedad y de tenencia. Contraposición que se expresaba sobre todo en el distinto grado de control que una y otra suponían. La primera se presenta como heredada, de libre disposición, ligada a un derecho que se dice hereditario (iure hereditario); la segunda a un derecho limitado en el tiempo y en la capacidad de disposición, se presenta como cedida, prestada. Los laicos alegan como propios los bienes en litigio basándose en la herencia familiar, en la compra, en la permuta o en la donación, es decir, distinguen en su patrimonio los bienes de abolengo o heredados y los ganados por cualquiera de esas formas. Podemos recordar a los hijos de Munio Velázquez. ante Alfonso VI invocando testamento commutacionis como base para reclamar a Sahagún la villa recibida por su padre ante el argumento monástico contrario de que no había habido permuta sino cesión vitalicia (teneret in uita sua). Ante la reina Urraca otro caballero alega también cambiatione frente a las pretensiones episcopales de que la villa disputada era de la catedral ex dato regum. O mucho más tarde, a principios del siglo XIII, los argumentos de un caballero que se defendía de las acusaciones monásticas de que tenebat per forcia diciendo set propria esse hereditas et ex paterno iture sibi successisse.

Las alegaciones eclesiásticas como vemos se concretan en lo que podría ser tomado por un discurso, que no una realidad, ya amortizador: sus bienes son de donacion hereditaria, sus concesiones son vitalicias. Sin embargo, no es un discurso eclesial como podría pensarse sino más bien señorial. Recordemos a la condesa Sancha a mediados del siglo XI, explicando ante la asamblea regia la transmisión hereditaria en la línea familiar de la villa disputada en cuyo nombre ella la demanda, y cómo sus contrincantes hablan igualmente de hereditates nostras propias, a pesar de que la condesa diga que las tenían de prestamo de suo patre.

Estamos ante una de esas cuestiones centrales a muchas de las discusiones historiográficas sobre el "cambio legal», especialmente aquellas que han pretendido dilucidar los orígenes del derecho de propiedad, derecho que para los argumentos más juridicistas, pero no únicamente, sólo aparece con la recepción del Derecho Romano a partir del siglo XII, cuando normas especifícas son invocadas tanto en las demandas y recusaciones como en la motivación de las sentencias, y cuando el cumplimiento de éstas era asegurado por un aparato político centralizado, antes no habría habido espacio para argumentos normativos dada la carencia de un derecho propiamente dicho, sustantivo, y la indistinción entre "hecho" y "derecho». Enn realidad, muchos argumentos

Hispania, LVIJ/3, núm. 197 (1997) 917-955 
parecen asumir que los conflictos se originan por esa carencia de normas claras. Gran parte de la crítica sobre la que se construye el llamado «modelo antropólogico» es una crítica a esta concepción ${ }^{65}$, paradógicamente ajurídica por normativista ${ }^{66}$, de las sociedades altomedievales.

En las disputas aqui comentadas observamos que, aun sin invocar normas explícitas, se tiene y se utiliza capacidad de razonar en términos legales, que las discusiones sobre hechos -tenencia o entramientos, por ejemplo-, aluden a reglas implícitas, a veces explícitas, sobre la legitimidad o no de los mismos. Un principio normativo que es aludido y opera de forma indirecta es el que trata de mantener los patrimonios señoriales definidos, prohibiendo, haciendo ilegales, los traspasos y tranferencias no autorizados. Principio que con carácter general para todo el reino elabora como estatuto y aplica como sentencia Alfonso VI en la famosa curia judicial de 1089 -ante la que el obispo de León, como hemos visto, lleva su grandem querelam contra la infanta Urraca- al ordenar que cada hereditas integra remaneret in iure et potestate domini sui sine alio herede, y definir los cuatro tipos de señoríos conocidos entre los que se prohiben dichas transferencias ${ }^{67}$. Norma que se muestra sistemáticamente incumplida en la práctica a pesar de ser ratificada en asambleas posteriores como la de Nájera de fines del siglo XII y ser recogida en ordenamientos tan romanizados como el de Alcalá de $1348{ }^{68}$.

De los foros ante los cuáles hemos visto se llevan estas demandas, sin embargo, parece poder deducirse que los grandes poderes eclesiásticos, como Sahagún o la catedral de León, o condales, no han logrado desarrollar una autoridad señorial capaz de imponerse sobre la nobleza, de variados niveles, a ellos vinculada al menos en los casos referidos al uso de la tierra. Lo que observamos es que durante el siglo XI y parte del XII los casos aquí comentados son llevados predominantemente ante la curia regia, y ante asambleas locales de hombres buenos, o a través de negociaciones directas bilaterales durante el siglo XII y buena parte del XIII, volviendo a llevarse ante el rey a fina-

65 Entre otros WHITE, S., ha criticado con singular maestria las tesis de los historiadores de] derecho británicos Milsom y Palmer en «Inheritances and Legal Arguments in Western France, 1050-1150», Traditio, 43 (1987) págs. 55-103.

th Sobre esta paradoja de gran interés el prólogo de RoBerts, S., a Bossy, T., (ed.) Disputes and Settlements. Law and Human Relations in the West. Cambridge, 1983.

67 1089/CL, 1244. Sobre esta decisión como expresión del desarrollo de la «propiedad dominjcal» ESTEPA, C., «Formación y consolidación» págs. 206-207. Sobre la Curia de Nájera como expresión de la consolidación del «dominio señorial» y bibliografia sobre la misma Alvarez, I., Poder y relaciones sociales, págs. 270-272. Una de las perspectivas desde la que estoy interesada en tratar estos problemas, sobre los que estoy trabajando, es como expresión de relaciones y alianzas trabadas por los campesinos fuera de los marcos señoriales reconocidos, ese acogerse a patronazgos diversos y los problemas de control que esa «movilidad» genera, subyacentes a muchas de las disputas que estamos tratando. Las pesquisas continuadas, a las que después me referiré, o las prohibiciones constantes de que pasen con sus heredades a otro señorío pnueban lo recurrente de estas prácticas.

68 Sobre estas regulaciones Pérez Prendes, J. M., Curso de Historia del Derecho Español, Madrid, 1989. Sobre algunos problemas de producción del derecho IGLesIA, A., «Derecho municipal, sefiotial, region, Historia, Instituciones, Documentos, 4, 1977. 
les de ese siglo. Esta información parecería confirmar el proceso que se pretende general de privatización de la justicia pública y su posterior recuperación por las instituciones monárquicas ${ }^{69}$. No obstante, hay que matizar esa impresión pues otros datos muestran que distintas instancias coinciden más que se suceden en el tiempo, que los hombres buenos aparecen también junto a los reyes, que la composición de esas instancias pudo variar con la identidad de los contendientes $u$ otras circunstancias que ignoramos ${ }^{70}$, y como hemos visto incluso los casos que llegan a la curia regia tienen soluciones locales antes y después del siglo XII, y no difieren sustancialmente en sus resultados de los casos dirimidos por otros medios extrajudiciales ". Más investigación es necesaria antes de concluir algo más firme sobre las relaciones entre casos disputados, identidad de los litigantes, instancias ante los que se llevan, procedimientos y resoluciones alcanzadas.

Entre los medios de prueba utilizados en estos procesos parece preferirse la pesquisa, la averiguación de la verdad de lo alegado o de lo escrito, ordenada - después de oídos los argumentos de las partes-por la autoridad que dirime el caso para decidir según la información de los testigos preguntados. El predominio de este tipo de prueba a lo largo de todo el período estudiado puede servir también para cuestionar la ruptura legal asociada con su adopción por un sistema judicial romanista que por ese hecho se considera más racional e imparcial que el anterior. Me parece, sin embargo, que más importante es entender la funcionalidad, la lógica, que su uso entraña en una sociedad cuyos grupos dominantes a distintos niveles necesitan hacer pública su dominación para poder ejercerla. Esta publicidad necesaria de las relaciones sociales, de los derechos sobre la tierra y dominio sobre los hombres en una sociedad de poderes tan fragmentados, se consigue sobre todo a través de inquisiciones periódicas de esos derechos con el fin de ratificarlos o reclamarlos si están perdidos. Es un tipo de actuaciones, no necesariamente debidas a un mandato judicial, más común de lo que se piensa si tenemos en cuenta que fueron promovidas de modo explícito en muchas concesiones de tierras. Recordemos que Munio Velázquez en 1055 había recibido de Sahagún en beneficio la villa, repetidamente disputada después por sus herederos, para inquirere y vindicare. Pero igualmente las concesiones de bienes específicos acompañadas muy a menudo con un vago et toto quanto puedas invenire pudieron provocar este tipo de averiguaciones como permite deducir la expresión venit tempus iudicandi que inquiriret unusquisque proximo sua hereditate alegada por la condesa Sancha en 1045 para justificar sus reclamaciones ${ }^{72}$.

69 Para ver como una apariencia similar en el Noroeste de Francia, que de ser cierta contrastaría con los métodos completamente informales que Cheyette documenta en la Provenza, es desmontada por $\mathrm{S}$. White mediante la aplicación de nuevas perspectivas de análisis, es muy útil su ya clásico artículo «Pactum...» pág. 285 y ss.

70 Vemos, por ejemplo, al obispo Diego disputar y negociar en las mismas fechas asuntos similares, con argurnentos y resoluciones parecidas, en un caso ante un concilio, tal vez el de León, del que desconocemos su naturaleza y composición, en otro ante la reina Urraca (1114/CL, 1347).

$" 1$ Remito a mi trabajo «Resolución de disputas...» donde se trata con más detalle este tema.

$721045 / \mathrm{CL}, 1026$

Hispania, LVII/3, núm. 197 (1997) 917-955 
Alusión que parece estar haciendo referencia a períodos de ejercicio de justicia señorial, durante los que la comunidad había de dar cuenta de sus tenencias y obligaciones, demarcar términos, usos, traspasos de heredades, transacciones diversas. Es posible que ese tempus se produjera a cada cambio de titular, de heredero, de concesionario, todo ello movería la memoria comunitaria, la ritualidad del poder y de la sumisión ${ }^{73}$. La costumbre de responder a encuestas de diverso tipo, ese preguntar a los más viejos, a los que vieron u oyeron, esa apelación al conocimiento público, a la pública fama, esa forma de construirse una verdad que era igual a derecho, tiene que ver con una cultura legal, cuyo conocimiento y extensión en tiempos posteriores profundiza Daniel L. Smail en otro de los artículos de este monográfico.

Pero esta información interesa además porque lo que se trasluce a través de estas inquisiciones es una corriente de transacciones con todo su correlato de forjamiento de alianzas y dependencias que parecen quedar fuera del control señorial, de imposibilitar esa estabilidad de dominios ordenada por las leyes, que hace de la realidad local un mundo más complejo del que aparentemente refleja la documentación ${ }^{74}$. Es teniendo en cuenta esta densa trama de intereses y relaciones sociales que es posible entender, tal cómo hemos intentado mostrar, no sólo como se originan y prosiguen estos conflictos sino también el caracter negociado de las resoluciones adoptadas que cierran, al menos momentáneamente, los litigios ${ }^{75}$. Son acuerdos por los que los nobles al tiempo que ven reconocido su poder local, tal vez previo al eclesiástico, se erigen en defensores del dominio de la institución a la que se vinculan. Es en esta diálectica de acoso/protección que hemos de entender las malfetrias y violencias nobiliarias ${ }^{76}$.

73 Cambios de titular regios parecen originar reclamaciones y pesquisas similares que nutren toda una retónica restauradora que se repite prácticamente a cada cambio de rey. De gran interés porque conectan con los temas aqui tratados las pesquisas ordenadas por Fernando I por estas fechas para recuperar heredades usurpadas o negadas a la catedral de Astorga (Blanco Lozano, P., Colección de Femando I, León, 1987, docs. 29 y 31). Igualmente las que ordena la reina Urraca en $1109 / \mathrm{CL}, 1328$ y 1329.

${ }_{74}$ Una inquisitio de bienes pertenecientes a la catedral de León en diversas villas, realizada entre otros por un arcediano de esa iglesia en tiempos de Alfonso VII, muestra bien lo que vengo diciendo, pues se detalla, por ejemplo, como en una de las villas inuenerunt tres kasas quas tenebant infanzones cum torto, que sunt de Santa Maria; o en otra terras que prendidit (...) de infantadigo cum torto otro infanzón, ([1140-1 157]/CL, 1431). En otra de estas inquisicio realizada a principios del siglo Xus se escribe que el prelado leonés en algunas villas es iniuiatur nobis milites heredes y armigeri eiusdem, pero también por clérigos y por los mismos vasallos episcopales $([1210-1232] / C L, 1815)$

75 Sobre la densidad de estas redes laicas en torno a los monasterios como marco principal para la acción política efectiva en el ámbito local vid. WHITE, «Feuding...» págs. 256 y ss. En mis trabajos sobre comunidades gallegas mostraba como la utilización de esta red por el gtupo monástico constituía el medio más eficaz y necesario de dominación, ALFonso, I., "Poder y diferenciación» (págs. 203-224) y en «La comunidad campesina» (págs. 305-372). Una investigación más amplia sobre redes monásticas en Galicia está siendo realizada bajo la dirección de R. Pastor.

${ }_{76}$ Un ejemplo a añadir de 1197 (CL,1734) referido al convenio (convenientiam) entre el obispo Manrique de León y el «mathechon» Gonzalo Femández, muestra bien esta dialéctica. El caballero devalve (relinquo) al obispo las heredades que requirebatis a me, quia dicebatis me tenere eas intuste, reconociendo esa injusticia, porque propria temeritatem intraueram, prometiendo integrar también todo lo que de malefactoriis quas uos cognoueretis quas ego eas feci, uel alicuis fecit 
Ciertamente, hay un dato que destaca en los textos que venimos analizando, la violencia atribuida a sus adversarios como elemento constante del discurso monástico, violencia que sirvió a los monjes para construir una imagen de sus enemigos tan eficaz que todavía, como señalábamos al principio de estas páginas, perdura en gran parte de nuestra historiografía. Así podemos ver que los litigantes de nuestros casos -los milites, infanzones o herederos-aparecen, incluso se reconocen, como homines forciosos que actuan per forcia, malitia y uiolenciam inducidos por zelo diaboli, como gentes que entran y possidebant iniuste of false retinuissent heredades monásticas y que pueden malmeter y desaforar a sus vasallos. Son acusados, pues, de cometer todo tipo de rapinis, injuriis, maleficiis y facinora cada vez, vimos, más asimiladas con pecados. Este lenguaje que utilizan para designar a sus agresores, les permite a la vez construir una imagen de sí mismos como víctimas pero también $-\mathrm{y}$ esto es quizás más importante- como misericordes que otorgan su gracia y perdón a los malhechores con los que negocian y constructores, por tanto, de relaciones pacíficas y amistosas. Este discurso de la violencia atribuida a los otros es, por tanto y en primer lugar, un recurso retórico, un medio de legitimar demandas propias y deslegitimar las del enemigo. Retórica no exclusivamente eclesiástica, aunque sea ésta la que mejor se ha conservado.

La violencia, sin embargo, se ha demostrado y nuestros documentos lo confirman, no era un simple útil retórico, era una táctica, una estrategia usada, no sólo por los laicos, en diferentes tipos de disputas, de contienda o intentio como términos más frecuentes en las comentadas. Se utilizaba para iniciar y proseguir hostilidades, pero también como medio de afirmar derechos o presionar para conseguirlos ${ }^{77}$. Los entramientos, por ejemplo, no tienen en sí mismos un significado negativo, ni tenían porque ser violentos. Entrar era el término legal para recibir y tomar posesión y así se practicaba ${ }^{78}$. La ilegalidad, por tanto, era algo discutible y por ello se disputaba en base a derechos contrapuestos ${ }^{79}$. Incluso si esos derechos no son explícitamente

mandato meo uel instinctu. Se compromete igualmente a hacer reparar o integrar a la catedral mala uero que homines mei fecerint que por inquisitionem inueneritis. El obispo como es habitual, attendens uoluntatem uestram bonam le concede en prestimonio otros bienes.

77 La dificultad de distinguir entre estas disputas por la tierta y otro tipo de luchas, enemistades, guerras o venganzas de sangre ha sido señalada por diferentes autores: GEARY «Vivre en conflict»; WHITE, en varios trabajos especialmente en «Feuding and Peacemaking», donde al señalar cómo la ideología y práctica de luchas pudieron facilitar el proceso por el que ciertos señores consolidaron la autoridad sobre sus clientes y extendieron su poder sobre los campesinos, critica interpretaciones puramente funcionalistas de estos conflictos que los ven como meras transacciones sociales. Un estudio extenso sobre la lógica de funcionamiento de estas hostilidades en MLLER, Bloodtaking, autor que señala el carácter moral, jurídico y siempre político de estas luchas (feuds) en pág. 183.

78 Esta heredad intrauit atque recepit por mano del portero regio dice, por ejemplo, un abad en 1188 (GonZáleZ, J., Alfonso VHI, dos. núm. 508, también núm. 408)

79 Los casos más evidentes y conocidos son las referidos a behetrias, cuando ante acusaciones monásticas de entramientos nobles éstos justifican esa actuación volviendo la acusación contra los monjes, argumentando que las heredades entradas habian sido compradas o adquiridas por los monjes ilegalmente en su señorio de behetria, pues era un hecho prohibido por derecho. Este tipo de alegaciones

Hispania, LVLI/3, núm. 197 (1997) 917-955 
invocados, existe un marco normativo, donde - como he señalado antes- las acusaciones y reclamaciones tienen sentido. Si se tiene esto en cuenta la violencia no puede considerarse simplemente como una práctica arbitraria y predatoria para imponerse sobre los campesinos, expresión de un señorío "unpolitical» como lo califica Bisson ${ }^{80}$, sino más bien una acción política en el proceso de competición interseñorial por ese dominio. Competición que como he tratado de mostrar en estas páginas se jugaba violenta y legalmente, pero no de forma necesariamente opuesta sino a menudo estrechamente imbricada.

Un mayor desarrollo del aparato institucional regio, intervención de gentes con cargos precisos, procedimientos más ajustados a «derecho" y capacidad de recurrir por falta de esas "formalidades legales" son cambios importantes en los procedimientos judiciales que se observan en la documentación de otros cenobios desde el siglo XIII ${ }^{81}$, merecedores sin duda de análisis más detallados que caen fuera de los objetivos de este trabajo, pero no deben ocultar los factores que hasta aquí he venido mostrando que condicionan y determinan formas y resultados de disputas y articulan y estructuran aspectos importantes de la vida política medieval entre los grupos dominantes.

El predominio de resoluciones pactadas, de compromisos también en los tribunales regios, que a veces parecen logrados después de formas tajantes de adjudicación, muestran el interés por renegociar relaciones preexistentes a través de estos procesos de naturaleza claramente política. Los testimonios de continuidad de estas formas de lucha y negociación judicial y extrajudicial que se documentan a lo largo de todo el período estudiado, antes y después del siglo XII, cuestionan la incidencia atribuida a los desarrollos legales e institucionales que se produjeron y anima a seguir estudiando de forma más compleja las relaciones indudables entre recursos institucionalizados y prácticas políticas.

normativas, como hemos visto, era utilizado para cualquiera de los señoríos conocidos. De los primeros me ocupe en «Resolución de disputas...»; más casos son comentados por ALVAREZ, I., en Poder y relaciones, págs. 298-300, que los ve como resultado de la complicación entre propiedad y seriorío.

80 T. Bisson a quien se debe una de las últimas formulaciones, aunque matizada, de los argumentos rupturistas, califica así este tipo de sefiorjo pues en su opinión es «an unpolitical mode of affective patrimonial power rooted in will instead of consensus» «The feudal revolution» Past and Present, 142 (1994), pág. 19. Una aportación crítica importante a partir de ese artículo la hace WhrTE, S., "Violence in Eleventh-Century France" en Past and Present, 152 (1996). Bisson insiste en sus argumentos en la contestación a White (Past and Present, 155, 1996) y en «The politicising of West European Societies (c.1175-c.1225)" en DuHamel-AMAdo, C. y Lobrichon, G., Georges Duby: L'écriture de l'histoire, Bruselas, 1996.

81 Referencias sobre Moreruela en ALFONSO, I., "Conflictos en el proceso de expansión de un señorio monásticos, Moneda y Crédito, 1977; sobre Carrizo documento 1281/506; sobre Oña en ALFONSO, I., «Resolución de disputas»; sobre otros cenobios castellanos como Silos o Las Huelgas en Alvarez, I., Poder y relaciones sociales. Es dentro del mundo eclesiástico donde se percibe una conciencia y una retórica legal más clara, donde se da una formulación teórica más acabada de los resultados que se esperan de la mayor institucionalización de los procędimientos de resolución y de la regulación de las normas a aplicar que se establecen para objetivar, despersonalizar formas de asignar y distribuir recursos que no son sólo económicos $(1120 / \mathrm{CL}, 1367)$ ver supra pág. 935.

Hispania, LVII/3, núm. 197 (1997) 917-955 